\title{
Flexible Active Power Control for PV-ESS Systems: A Review
}

\author{
Xiangqiang Wu and Tamas Kerekes*(D) \\ Department of AAU Energy, Aalborg University, 9220 Aalborg, Denmark; xiwu@energy.aau.dk \\ * Correspondence: tak@energy.aau.dk
}

\begin{abstract}
The penetration of solar energy in the modern power system is still increasing with a fast growth rate after long development due to reduced environmental impact and ever-decreasing photovoltaic panel cost. Meanwhile, distribution networks have to deal with a huge amount and frequent fluctuations of power due to the intermittent nature of solar energy, which influences the grid stability and could cause a voltage rise in the low-voltage grid. In order to reduce these fluctuations and ensure a stable and reliable power supply, energy storage systems are introduced, as they can absorb or release energy on demand, which provides more control flexibility for PV systems. At present, storage technologies are still under development and integrated in renewable applications, especially in smart grids, where lowering the cost and enhancing the reliability are the main tasks. This study reviews and discusses several active power control strategies for hybrid PV and energy storage systems that deliver ancillary services for grid support. The technological advancements and developments of energy storage systems in grid-tied PV applications are also reviewed.
\end{abstract}

Keywords: PV integration; energy storage systems; flexible active power control; frequency regulation

check for

updates

Citation: Wu, X.; Kerekes, T. Flexible Active Power Control for PV-ESS Systems: A Review. Energies 2021, 14, 7388. https://doi.org/10.3390/ en14217388

Academic Editors: Ignacio Mauleón and Eduardo F. Fernández

Received: 29 August 2021

Accepted: 3 November 2021

Published: 5 November 2021

Publisher's Note: MDPI stays neutral with regard to jurisdictional claims in published maps and institutional affiliations.

Copyright: (C) 2021 by the authors. Licensee MDPI, Basel, Switzerland. This article is an open access article distributed under the terms and conditions of the Creative Commons Attribution (CC BY) license (https:/ / creativecommons.org/licenses/by/ $4.0 /)$.

\section{Introduction}

PV energy has grown rapidly in the last few years and has occupied quite a proportion of the electricity market in some regions and power systems. For example, according to statistics in [1], PV systems have had a significant growth in total capacity from approximately $39 \mathrm{GW}$ in 2010 to $760 \mathrm{GW}$ in 2020. This development has been possible thanks to the cost reduction and efficiency increase in the PV modules and favourable regulations from local governments (e.g., increasing feed-in tariffs and investment in renewable energy technologies).

However, as the penetration of solar energy is increasing, it will bring new challenges for the reliable and stable operation of the connected power grid [2,3]. Conventionally, the power control of PV systems usually adopt maximum power point tracking (MPPT) to maximize the energy yield. However, the power production of PV systems during MPPT operation will follow fluctuations of the atmospheric conditions, which cannot be controlled. This fluctuation in input power will challenge the power quality of the electrical system and influence stability, especially in weak grid conditions, which means low short circuit ratio (SCR) at point of common coupling (PCC) [4]. For example, PV production in peak power hours may cause overloading in the distribution network, which can induce voltage rise and damage the domestic appliances [5]. Furthermore, the rapid changing of solar irradiance (e.g., due to passing clouds) can cause voltage fluctuation in the power grid [6]. In addition, the losing inherent inertia is another concern, with the rotating synchronous generators (SGs) being replaced by PV systems [7].

In order to ensure stability and reliability of the grid, integrating energy storage systems (ESS) into PV systems is one possible solution, as they can provide more control flexibility. For example, ESS can provide additional power when PV production is insufficient (e.g., in rainy days) and absorb surplus energy in peak power generation hours. In this way, ESS can be controlled to regulate the output power of the PV-ESS systems according to specific grid codes, thus the reliability of the grid can be improved. At present, 
considering the cost and aging problem of the commonly used energy storage technologies (e.g., Li-ion battery), mixed energy storage systems can be a more cost-effective solution in combination with PV systems, which improves the performance and reliability of the overall system and reduces the operation and maintenance cost.

Another solution to enhance the stability and reliability of the grid is to adopt flexible active power control strategies. In recent years, countries with a significant proportion of installed renewable energy sources have launched mandatory requirements for renewable energy generation systems including PV systems [8-11]. In recent grid technical regulations, several active power control functions are introduced to achieve flexible PV integration into the grid, which are power reserve control, power-limiting control, power ramp-rate control, and other ancillary services for frequency support. Based on the functionalities, many control schemes are proposed [12-14]. However, these methods have limitations in some specific situations and need to be further improved. For example, these control methods shift the operation point of the maximum power point (MPP), thus the total energy yield will be reduced, which decreases the utilization of solar energy, meaning a loss of revenue for the plant owner. In this regard, ESS can be integrated to provide various support functions to the grid, according to the commands from distribution system operators.

This paper mainly reviews the application of energy storage solutions with PV systems (PV-ESS). The remainder of this paper is organized as follows: Section 2 presents the configuration of the PV and ESS integration, where different topologies of PV-ESS systems are compared. Section 3 reviews the flexible active power control strategies for PV-ESS systems, where open issues are also discussed. In Section 4, frequency regulation methods, which usually imitate the control loops of SGs, are briefly reviewed. Future trends of flexible power control for PV systems are discussed in Section 5, which forms the conclusion of this paper.

\section{Configuration of PV-ESS Systems}

Structurally, topologies of PV-ESS integration systems can be roughly divided into four categories, as shown in Figure 1. In [15], AC-parallel integration was discussed, where the ESS was connected with the grid through a bidirectional DC / AC inverter and a bidirectional buck-boost DC /DC converter. This topology has high flexibility on system layouts because the ESS is not necessary to be placed in close proximity to PV arrays. Literature [16] adopted the DC-parallel integration, where the ESS was connected to a DC bus through a buck-boost DC/DC converter, while PV arrays were connected to the same DC bus using a unidirectional DC/DC converter. This integration increased the overall efficiency compared to Figure 1a due to reduced number of converters. Literature [17] proposed an in-line integration topology. In this topology, an ESS was connected in parallel with the DC bus without a voltage-boosting stage, which has advantages in residential applications due to the decreased hardware cost. Literature [18] adopted an AC-series integration, in which the ESS was integrated into a multilevel converter through a modular converter. In this way, the system is very flexible due to the modular structure, and PV arrays can maximize their output, while the ESS, in cases of stand-alone/island operation, can automatically regulate the voltage and frequency of the grid voltage according to the load demand. 
(a)
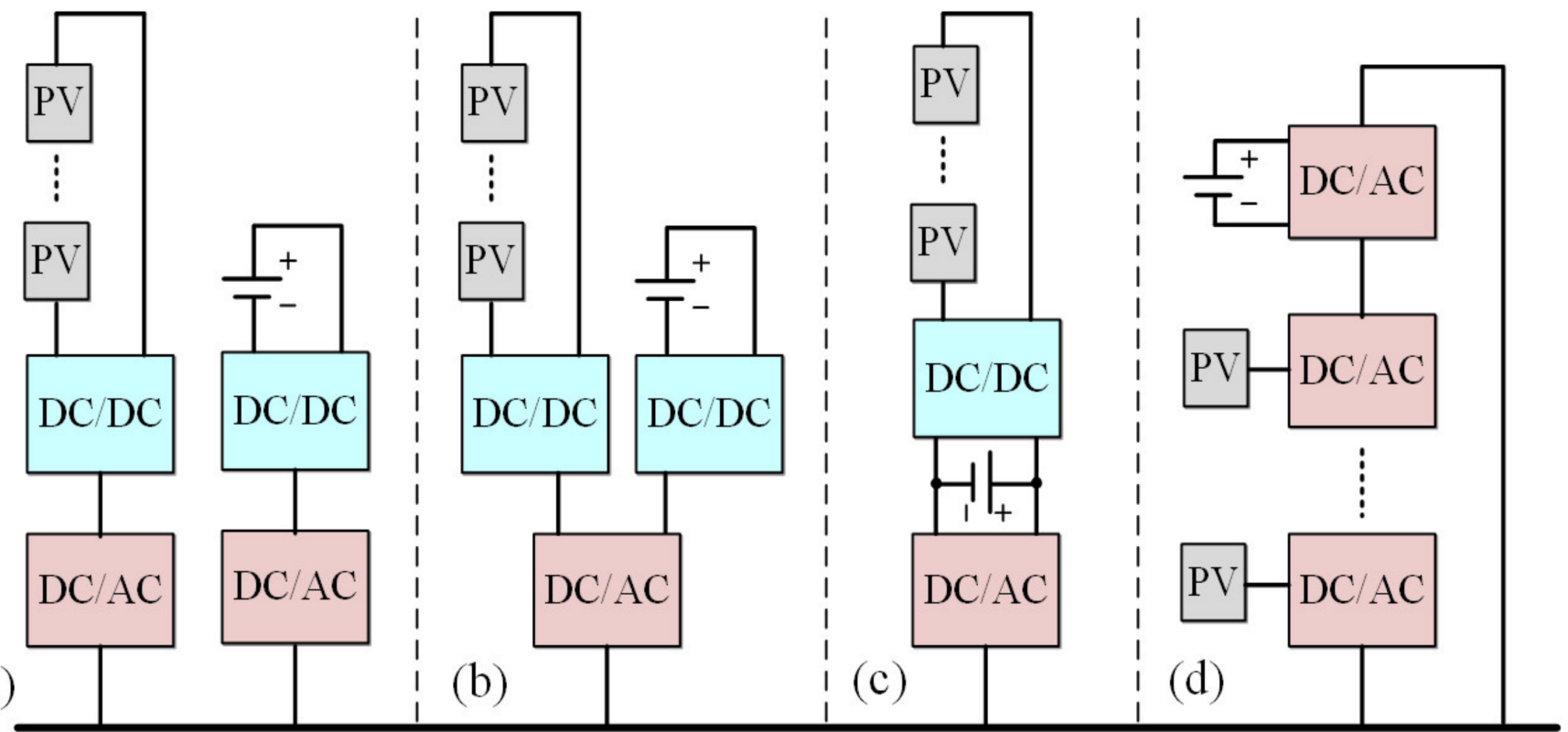

Figure 1. State-of-the-art of PV integration with ESS. (a) AC-parallel integration. (b) DC-parallel integration. (c) In-line integration. (d) AC-series integration.

Recently, in order to reduce the size of power converters and improve the power density of PV systems, some scholars proposed new topologies based on multiport converters. Literature [19] proposed a DC-series integration topology for a PV-battery system, as shown in Figure 2a. In this approach, the PV modules are connected in series with the ESS, whose output is connected in parallel with a current compensator. Thus, the battery does not require any voltage-boosting stage (e.g., buck-boost converter) and will support the PV string voltage to provide more flexibility to the grid. Similarly, literature [20] proposed an optimized DC-parallel integration method, as shown in Figure $2 b$. The voltage difference between PV modules is compensated by the current compensator, so as to realize the MPPT control of each PV module. In [21], inspired by the in-line integration, a back-to-back topology was proposed to integrate PV and the ESS, as shown in Figure 2c, where the PV-ESS system could work in grid-connected or standalone mode by controlling the grid-tied switch. When working in standalone mode (i.e., DC microgrid), the load voltage and the state of charge of batteries can be regulated based on the demand and supply management schemes. Literature [22] used a triple-active bridge topology to integrate PV, battery, and loads shown in Figure 2d. With this three-port isolated converter, the power of each port can be individually regulated, which increased the control degree of freedom. Based on the proposed stability control strategy, the PV panels harvested as much power as possible, and a stable system operation can be ensured by controlling the power exchange between different ports.

However, due to the changing environmental conditions (e.g., solar irradiance and temperature), there exists frequent power fluctuations and mismatch between power generation and demand, which requires more focus on dynamic response and energy capacity. Besides, the cost and battery lifespan should be taken in account. Table 1 concludes the characteristics of the commonly used energy storage technologies in renewable energy generation applications, including lithium-ion battery, vanadium redox battery (VRB), lead-acid battery, and supercapacitor (SC). It can be seen from Table 1 that different energy storage technologies have great differences in energy and power density, lifespan, response dynamics, and price, which indicates that none of them can meet all the aforementioned requirements. 


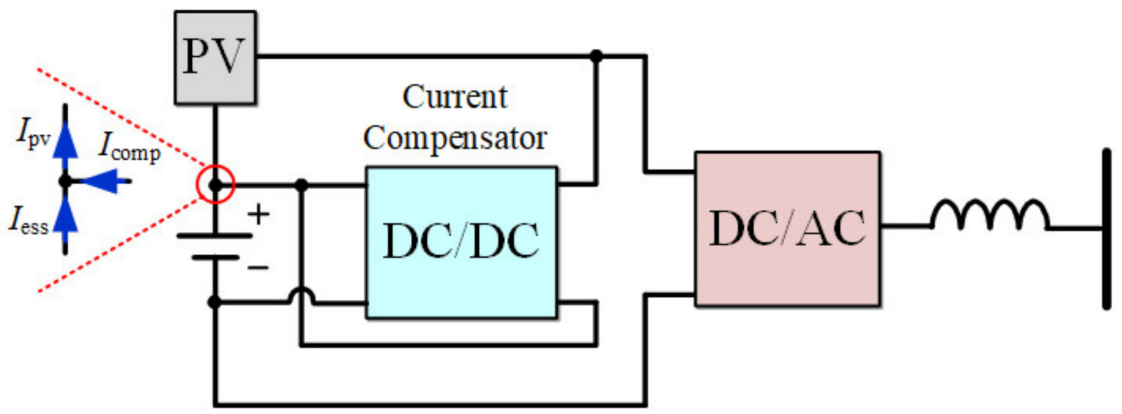

(a)

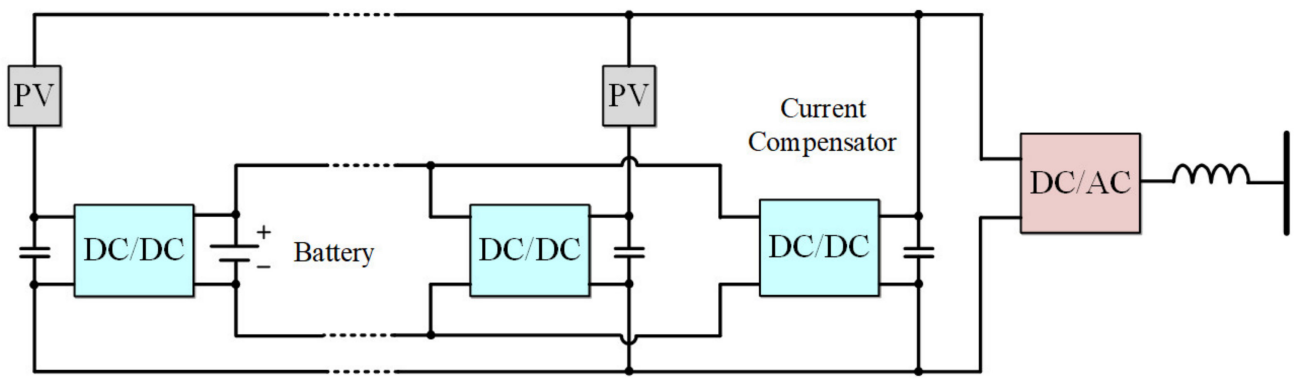

(b)

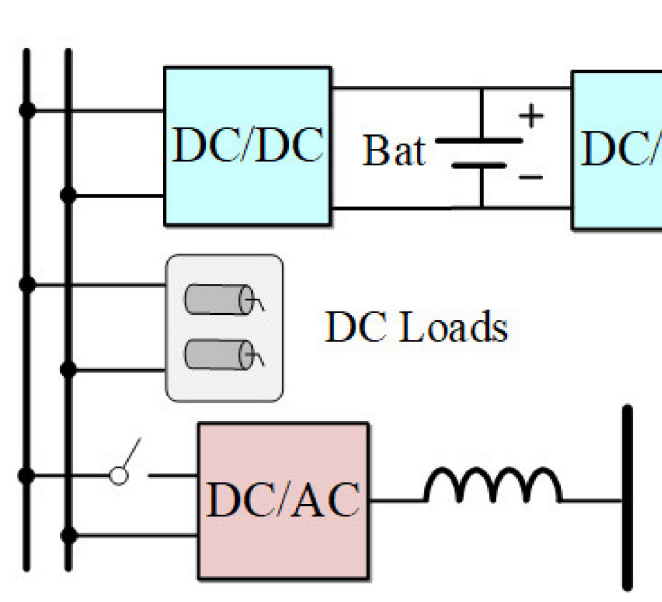

(c)

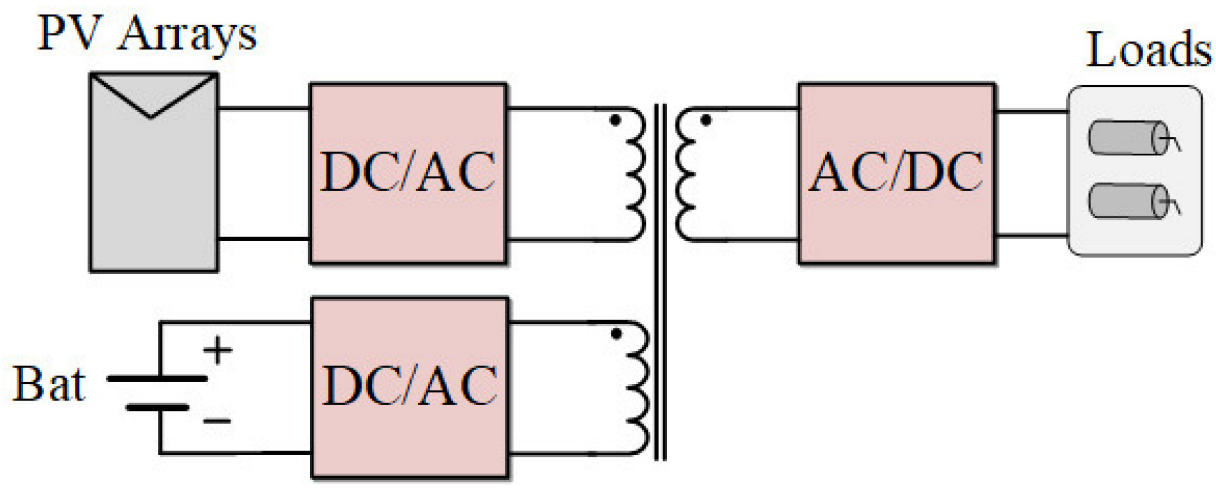

(d)

Figure 2. Examples of novel PV-ESS integration. (a) Proposed topology in [19]. (b) Proposed topology in [20]. (c) Proposed topology in [21]. (d) Proposed topology in [22]. 
Table 1. Characteristics of different ESS elements [23-25].

\begin{tabular}{ccccc}
\hline Parameters & Lead-Acid Battery & Li-Ion Battery & VRB & Supercapacitor \\
\hline Energy density $(\mathrm{Wh} / \mathrm{kg})$ & $10-100$ & $150-400$ & $20-70$ & $10-20$ \\
\hline Power density $(\mathrm{W} / \mathrm{kg})$ & $90-700$ & $1000-5000$ & $1-10$ & $4000-10,000$ \\
\hline Cycle life & 1000 & 5000 & $>10,000$ & $>500,000$ \\
\hline Cycle efficiency & $70-90 \%$ & $90-99 \%$ & $60-85 \%$ & $\mathrm{~h}-98 \%$ \\
\hline Charge $/$ discharge time & min-h & min-h & 150 & 2500 \\
\hline Price $(\mathrm{USD} / \mathrm{kWh})$ & 100 & 600 & & $\mathrm{~s}$ - \\
\hline
\end{tabular}

In order to develop the advantages of different energy storage technologies and bypass their shortcomings, multiple types of storage technologies can be combined to complement each other and form a hybrid ESS (HESS). Depending on requirements of reallife applications, different types of hybrid energy storage systems can be formulated [26]. Literature [27] adopted a HESS consisting of lead-acid batteries and VRB to suppress the power fluctuation. Aiming to minimize the overall cost of installation and maintenance, an optimal capacity allocation model for the economic operation was established, which proved the effectiveness of reducing investment in power plants. Literature [28] proposed a HESS combined with lead acid battery and nickel cadmium battery, which showed longer charge/discharge life cycle compared with a single battery. Literature [29] used Li-ion batteries and superconducting magnetic energy storage to suppress wind power fluctuation based on an empirical mode decomposition algorithm. In [30], a HESS consisting of VRB and SC was adopted to reduce the fluctuations in output power of PV plants, which showed an increased overall efficiency. Literature [31] proposed a multi-timescale hybrid energy storage power coordination control strategy based on a HESS including compressed air, battery, and supercapacitor to smooth out the power fluctuation. Although the effectiveness of different types of HESS have been proven, it should be noted that combinations of energy storage technologies should be determined according to specific applications, and there is no optimal HESS that fits all scenarios.

At present, the most commonly used HESS usually consist of batteries and supercapacitors, because they can complement each other in dynamics, lifespan, capacity, and cost, which makes this combination very cost effective. In this regard, based on DC-parallel integration presented in Figure 1b, literature [32] classified different hybrid battery-SC topologies into three types, as shown in Figure 3. The passive HESS connection has the lowest hardware cost without any additional DC/DC stage, but needs a high battery voltage, which is not suitable in household applications. The active connection has a wide operating voltage range, which makes the best of the energy storages. Moreover, [33] compared the battery lifetime and cost of different HESS topologies during a day, which indicated that semi-HESS perform at a lower cost than passive HESS systems. Ref. [34] investigated the annual storage cost, which showed the unit cost of battery-SC with active HESS topology is lower than that of the battery-only case. 


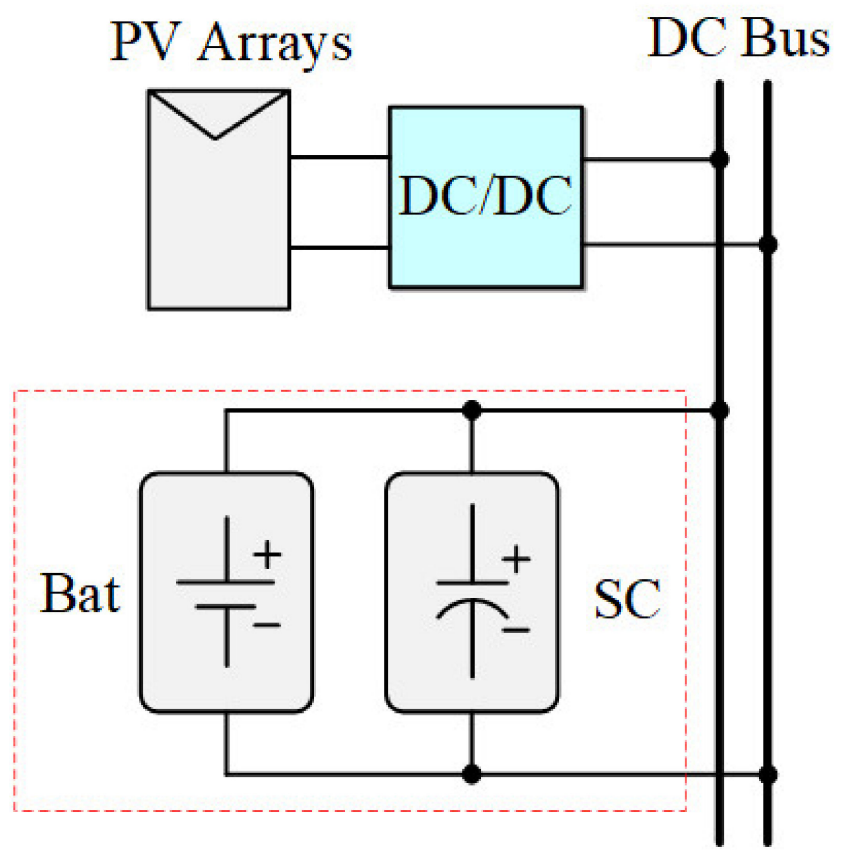

(a)
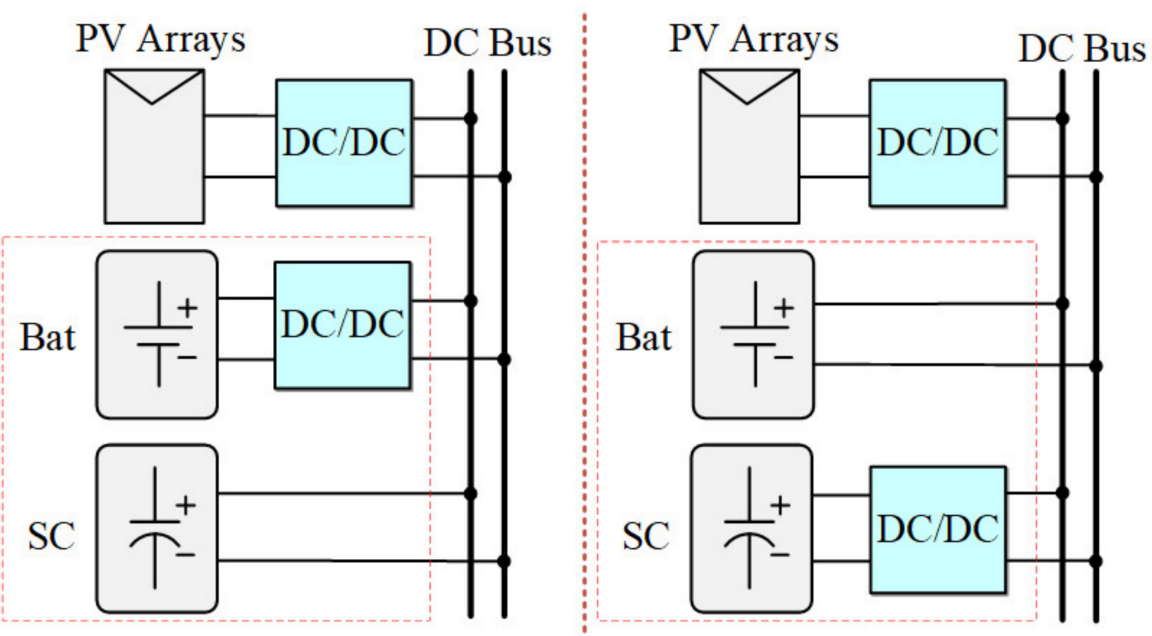

(b)

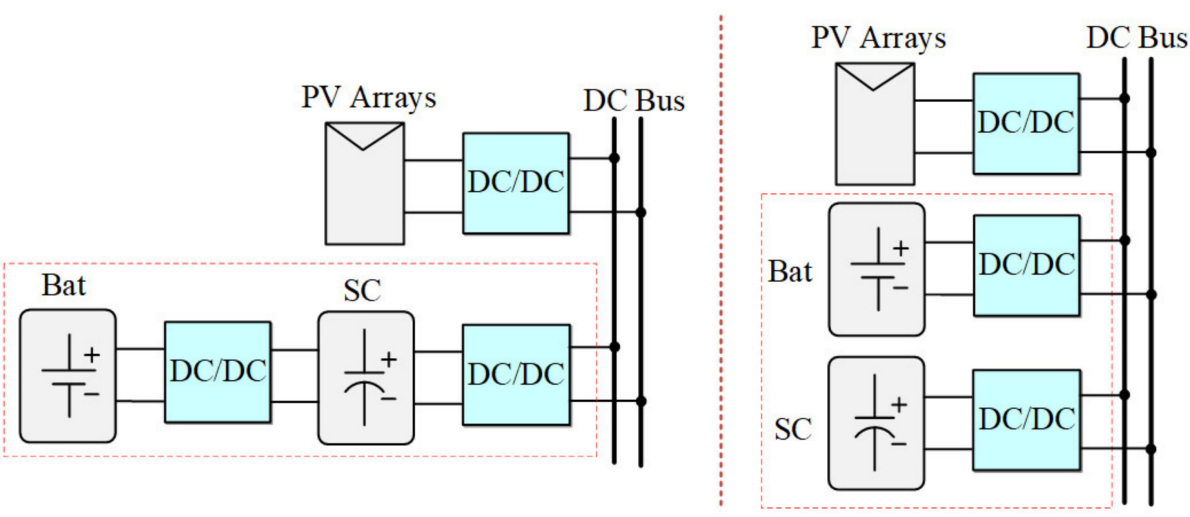

(c)

Figure 3. Configuration of the battery-supercapacitor HESS topologies. (a) Passive HESS. (b) Semiactive HESS. (c) Active HESS. 


\section{Flexible Active Power Control Methods}

In order to avoid instability or overloading and improve the flexibility of distribution networks, PV power plants must be equipped with constraint functions. Countries with a large proportion of installed renewable energy share (e.g., Denmark, Germany, Austria, China) have a series of technical regulations for the PV power plants operation [8-11]. For example, the active power control requirements in Denmark are shown in Figure 4, where the constraint functions are divided into power reserve control (delta power constraint), power ramp-rate control, and power-limiting control (absolute power constraint). The control strategies based on these constraint functions will be reviewed in this section.

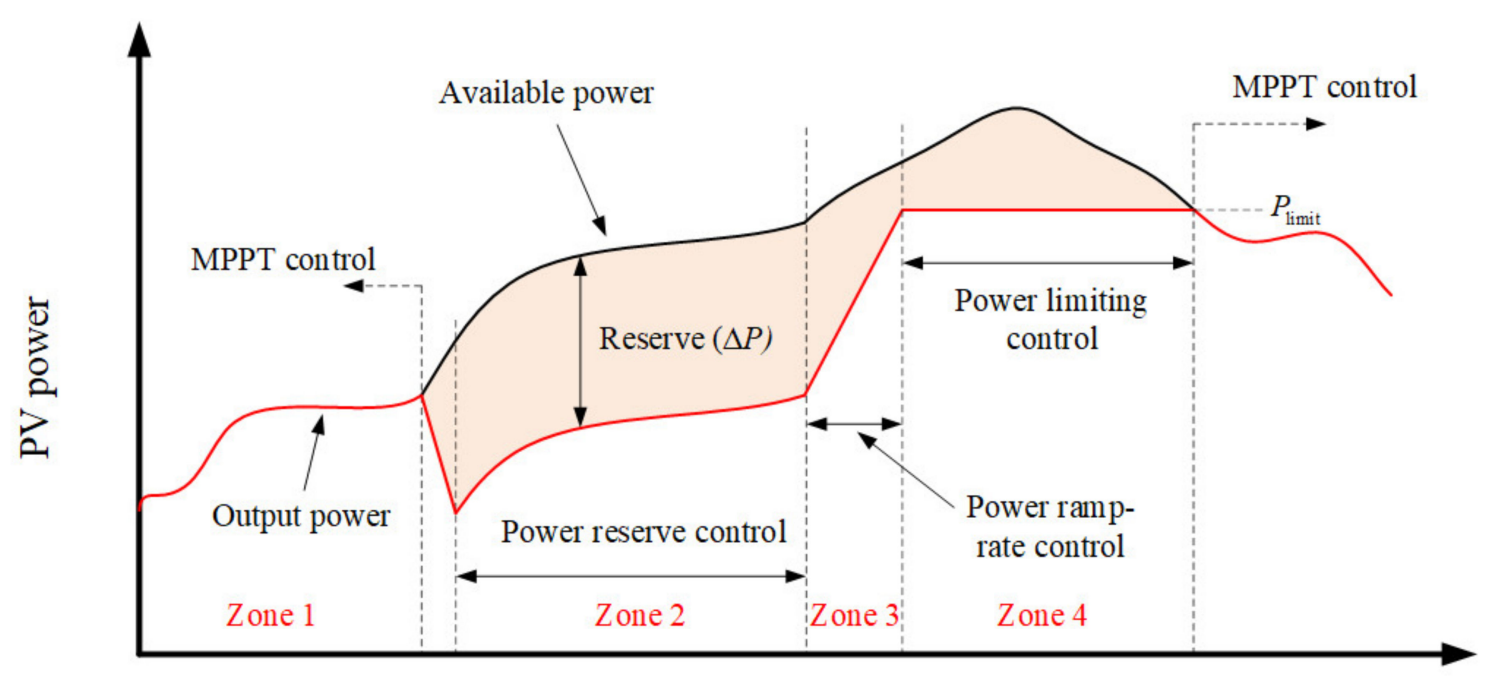

Time

Figure 4. Active power control functions of PV systems defined in Danish grid code.

\subsection{Power Reserve Control}

As shown in Zone 2 of Figure 4, the power reserve control (PRC) will keep a constant power reserve during operation, which increases the virtual inertia capacity for potential grid support and thus improve the reliability of the distribution power system.

In order to keep a constant power reserve $\Delta P$, the instantaneous $P V$ output power $p_{\mathrm{pv}}$ needs to be reduced according to the available PV power $p_{\text {avai }}$, which can be represented as:

$$
p_{\mathrm{pv}}=p_{\text {avai }}-\Delta P
$$

Therefore, the power reserve control strategy can be achieved by adjusting the PV voltage reference according to the modified MPPT algorithm, where the PV voltage reference can be expressed as:

$$
v_{\mathrm{pv}}^{*}=\left\{\begin{array}{cl}
v_{\mathrm{mpp}}^{*} & {\left[p_{\mathrm{pv}} \leq p_{\text {avai }}-\Delta P\right]} \\
v_{\mathrm{pv}}-v_{\text {step }} & {\left[p_{\mathrm{pv}}>p_{\text {avai }}-\Delta P\right]}
\end{array}\right.
$$

where $v_{\mathrm{mpp}}^{*}$ is the voltage reference from an MPPT algorithm, and $v_{\text {step }}$ is the perturbation size.

In this approach, acquiring the instantaneous maximum power point is the premise to ensure the required power reserve. In the prior-art work, there have been some methods to estimate the maximum power point (MPP) explored to realize power reserve control without energy storage, including some model-based methods (e.g., sky camera or ground sensor-based forecasting, empirical model-based estimating, P-V curve fitting), masterslave strategy, and the perturb and observe $(\mathrm{P} \& \mathrm{O})$ method [35-38]. The pros and cons of these methods are summarized in Table 2. 
Table 2. A summary of PRC methods.

\begin{tabular}{|c|c|c|}
\hline Methods & Advantages & Disadvantages \\
\hline P-V curve fitting [35] & $\begin{array}{l}\text { Good robustness } \\
\text { Reduced hardware cost }\end{array}$ & $\begin{array}{l}\text { Heavy computational burden } \\
\text { Sensitive to parameters of PV arrays } \\
\text { Dependent on sampled points }\end{array}$ \\
\hline Empirical model-based estimating [36] & Reduced hardware cost & $\begin{array}{l}\text { Heavy computational burden } \\
\text { Big data needed } \\
\text { Sensitive to parameters of PV arrays }\end{array}$ \\
\hline Sensor-based forecasting [37] & Real-time measurement & $\begin{array}{l}\text { Extra cost of sensors } \\
\text { Complexity }\end{array}$ \\
\hline Master-slave strategy [12] & $\begin{array}{c}\text { Simple } \\
\text { Real-time measurement }\end{array}$ & $\begin{array}{c}\text { Communication needed } \\
\text { Dependent on entire system configuration }\end{array}$ \\
\hline P\&O method [38] & $\begin{array}{c}\text { Good robustness } \\
\text { Reduced hardware cost }\end{array}$ & Power and voltage impulses in DC link \\
\hline
\end{tabular}

It can be seen from Table 2 that the former three methods require the availability of big data or are highly dependent on the accuracy of PV characteristics, which may deviate over time. The master-slave strategy can estimate the available PV power in real time and is usually applied to multi-string PV systems. In residential applications, the P\&O method is a more promising way to estimate the PV available power, whose principle is illustrated in Figure 5. In this algorithm, a perturbation is made in the operating point of the PV system, and then, the new power is measured and compared to the previous value to determine the perturbation direction. Thus, the MPP of the PV system under specific solar irradiance and temperature can be estimated. In Figure 5, the MPPT control is periodically employed, and every time the maximum power point is measured, the PV system will switch to the power reserve mode immediately. In this way, a certain amount of PV power can be reserved.

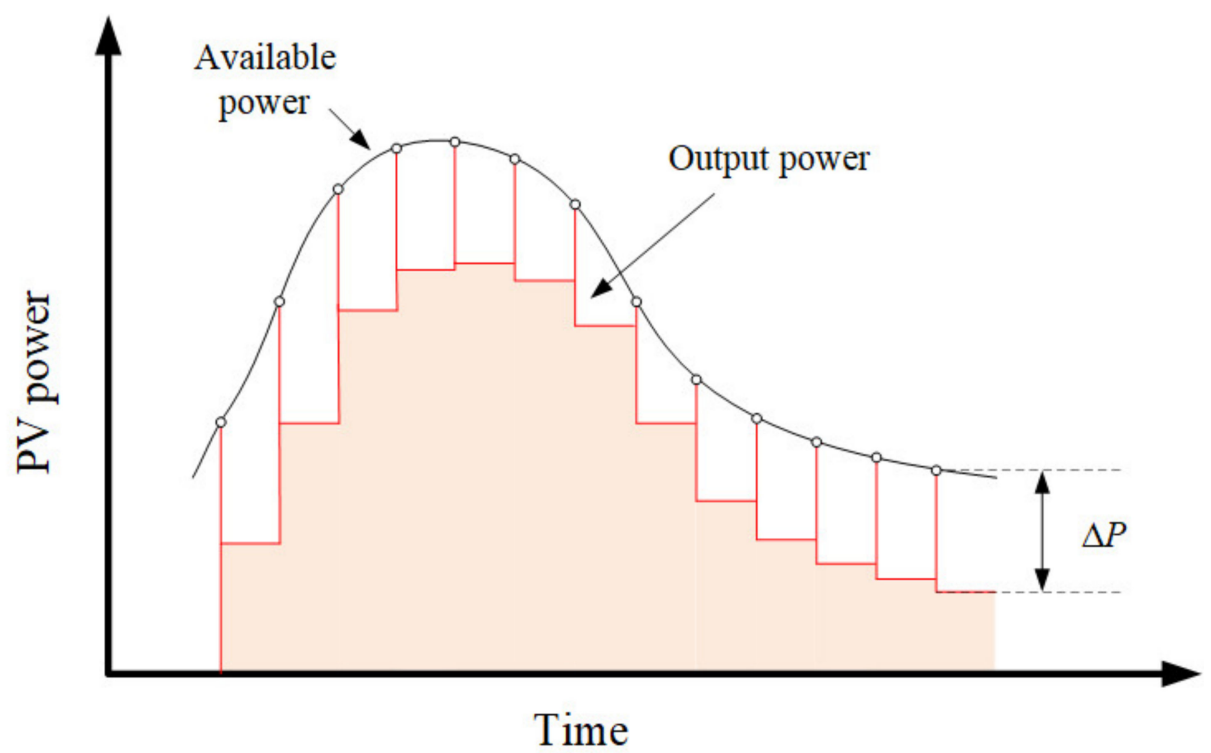

Figure 5. Principle of power reserve control with $\mathrm{P} \& \mathrm{O}$ algorithm.

However, as shown in Figure 5, it is inevitable that the transient power impulses will be introduced during the PRC mode. These periodical impulses will challenge the power quality and the stability of the grid and will decrease the lifespan of power electronics devices in the long run. Therefore, the power impulses have to be eliminated properly. As an effective solution to this, ESS can be integrated into PV system. In this regard, literature [39] adopted a capacitive DC link to store the peak power and damp the impulses. However, the storage of a DC link capacitor is limited, and the fluctuation in DC voltage 
may exceed the safe range when the reserved power is large. Moreover, the frequent charge and discharge of a DC link capacitor will adversely affect its lifespan and the output power quality. Literature [40] proposed a control solution for grid-connected microgrids, where an SC-based ESS was used to deal with the transient power exchange so that the robustness and reliability of the system was increased. Literature [41] used a Li-ion battery ESS to provide active power reserve, while the PV arrays operate at MPPT. Nevertheless, in this case, the reserved power is completely restored in the battery ESS, which is a costly solution due to the redundancy capacity of ESS. In [42], a battery-SC HESS was used to realize an inertia emulation control, in which the battery was used to deal with the slow-changing power variations, while SC was used to deal with the fast-changing power variations (i.e., power impulses). In this solution, the HESS has shown good performance, where the efficiency and lifetime of the battery was increased, and the reliability of the PV system can be enhanced.

\subsection{Power Ramp-Rate Control}

As shown in Zone 3 of Figure 4, the power ramp-rate control (PRRC) is introduced to limit the PV power change rate, so as to reduce the voltage fluctuation in distribution networks. During this control mode, the power change rate is limited within a given value $R_{r}^{*}$. The power change rate $R_{\mathrm{r}}$ is defined as the ration of the power difference measured $\Delta p_{\mathrm{pv}}$ to the time period $\Delta t$, which can be expressed as:

$$
R(t)=\frac{\Delta p_{\mathrm{pv}}}{\Delta t}
$$

The principle of PRRC summarized as: when the power change rate is below the ramp-rate limit, the MPPT algorithm will be employed; when the change rate is over the limit, the output power of PV systems should be reduced immediately, until the power change rate meets the required ramp-rate limit. In order to achieve this function, a modified MPPT algorithm can be adopted, where the operation points of PV systems can be adjusted by regulating the PV voltage $v_{\mathrm{pv}}^{*}$. The principle of PRRC can be expressed as:

$$
v_{\mathrm{pv}}^{*}=\left\{\begin{array}{cl}
v_{\mathrm{mpp}}^{*} & {\left[R(t) \leq R_{r}^{*}\right]} \\
v_{\mathrm{pv}}-v_{\text {step }} & {\left[R(t)>R_{r}^{*}\right]}
\end{array}\right.
$$

where $v_{\mathrm{mpp}}^{*}$ is the output voltage provided by the MPPT algorithm, and $v_{\text {step }}$ is the perturbation voltage.

Clearly, the PRRC algorithm can only function in the power ramp up conditions due to the power curtailment. When the PV production decreases, predicted solar irradiance or additional power will be needed to control and maintain the ramp-down power rate. In order to limit the ramp rate in decreased solar irradiance, one way is based on the ground-forecasting systems to predict the ramp down events and curtail the PV production in advance. Another way is to integrate ESS into PV systems. In this regard, literature [43] proposed a forecasting-based active power curtailment (FAPC) method, which can make the energy storage equipment redundant. The principle of the FAPC method is shown in Figure 6, where $P_{\mathrm{pv} 1}$ and $P_{\mathrm{pv} 2}$ denote the available PV power at the high solar irradiance and low irradiance conditions (e.g., during cloud shadow), respectively. The FAPC method is a cost-effective solution, since it can curtail the power before the solar irradiance sharply decreasing, and it does not require ESS or only minimum ESS. Therefore, the reliability of the entire system can be improved as the number of potentially faulty components is reduced. However, without storage, the self-consumption in PV systems becomes lower due to the loss of curtailed energy. In some cases, the economic losses caused by the power curtailment may offset the benefits of reduced equipment costs. 


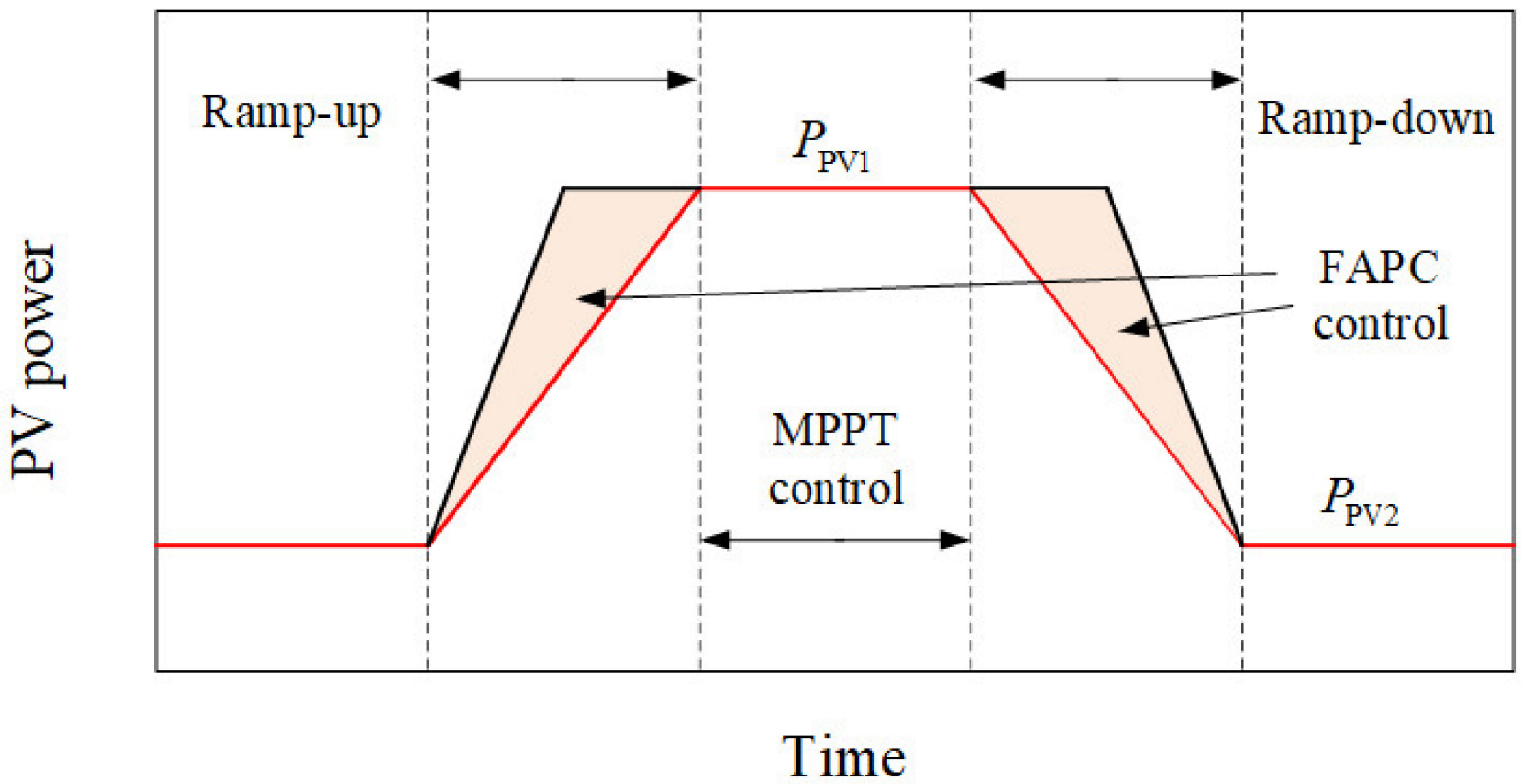

Figure 6. Principle of FAPC method in [43].

Generally, the ESS is used for PRRC implementation by absorbing or injecting power to smooth the fluctuation. The framework of ESS-based PRRC in most cases is shown in Figure 1b, where various smoothing methods can be adopted to regulate the power exchange of ESS and the DC bus. Additionally, the principle of ESS-based PRRC is shown in Figure 7.

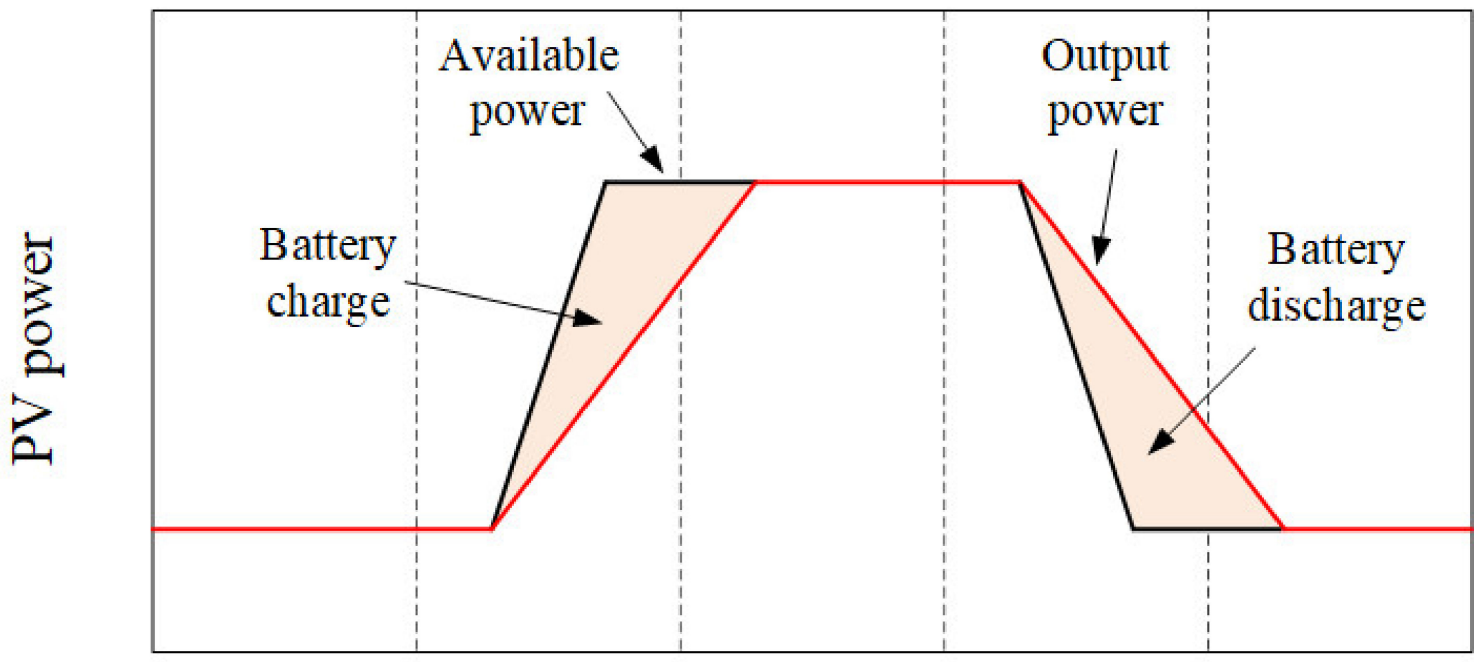

\section{Time}

Figure 7. Principle of the ESS-based PRRC method.

In prior-art work, the PV smoothing algorithms with ESS can generally be categorized into two types: filter-based methods [44-47] and gradient methods [48]. Filter-based methods are used in most applications with ramp-rate constraints, where the instantaneous power of PV production are filtered and then provided to the ESS as a power reference. There have been many filter-based methods developed and discussed in ramp-rate control cases. Commonly used filter-based methods include moving average (MA) filter-based algorithms (e.g., MA, exponential MA, i.e., EMA), low-pass filter (LPF)-based algorithms 
(e.g., LPF, second-order LPF, i.e., 2-LPF), and some other filter-based methods. The gradient methods directly compensate the needed power to limit the power ramp rate according to the instantaneous derivatives of the PV output power, which indicates that this kind of method does not filter the PV output power. The comparison of different ESS-based PRRC methods is summarized in Table 3.

Table 3. A comparison of power smoothing methods.

\begin{tabular}{|c|c|c|}
\hline Methods & Advantages & Disadvantages \\
\hline MA [44] & $\begin{array}{c}\text { Simplicity } \\
\text { Small computational burden }\end{array}$ & Rely on previously sampled data \\
\hline EMA [45] & Simplicity & $\begin{array}{c}\text { Large ESS required } \\
\text { Poor ability to regain SOC of ESS }\end{array}$ \\
\hline LPF [46] & $\begin{array}{l}\text { Suppress high-frequency power } \\
\text { fluctuations }\end{array}$ & $\begin{array}{c}\text { Large ESS required } \\
\text { Sensitive to irradiance variations }\end{array}$ \\
\hline 2-LPF [47] & $\begin{array}{c}\text { Suppress higher-frequency power } \\
\text { fluctuations } \\
\text { ESS capacity reduced } \\
\text { Long life expectancy of ESS } \\
\text { Fast dynamics }\end{array}$ & Sensitive to irradiance variations \\
\hline Gradient control [48] & Independent of past irradiance data & $\begin{array}{c}\text { Complexity } \\
\text { Short life expectancy of ESS }\end{array}$ \\
\hline
\end{tabular}

It can be seen from Table 3 that the 2-LPF method has a better performance with fast dynamics and long life expectancy of ESS. Furthermore, in order to enable more costeffective PV systems, many types of energy storage technologies have been integrated with PV systems apart from a battery, such as superconducting magnetic energy storage [49] or an electrochemical capacitor [50]. Recently, it has been more popular to integrate hybrid ESS into PV systems instead of single ESS. For example, a multiple ESS was used in [51] to limit the ramp rate of PV output power at different time scales and proposed a coordination strategy to optimize the ESS capacity. In [52], a hybrid (battery and ultracapacitors) ESS was used for ramp-rate control in PV plants, and a techno-economic model was presented to compare the cost-effectiveness of HESS with different capacities. These attempts have proven the feasibility and cost-effectiveness of HESS in power ramp rate control applications. Therefore, there is the possibility to explore more power smoothing methods or coordination strategies between PV and ESS to achieve a better performance of ESS-based PRRC in PV systems.

\subsection{Power-Limiting Control}

As depicted in Zone 4 of Figure 4, the power-limiting control (PLC) is typically used to avoid overloading in distribution networks. Through the MPPT operation, the output reference can be the PV power $p_{\mathrm{mpp}}^{*}$, current $i_{\mathrm{mpp}}^{*}$, and voltage $v_{\mathrm{mpp}}^{*}$. As a consequence, these three variables can be adopted to realize the PLC operation. In the prior-art work, the PLC strategies adopted in the literatures can fall under three approaches, as shown in Figure 8, which are direct power control [53], current-limiting control [54], and modified MPPT strategy [55]. 


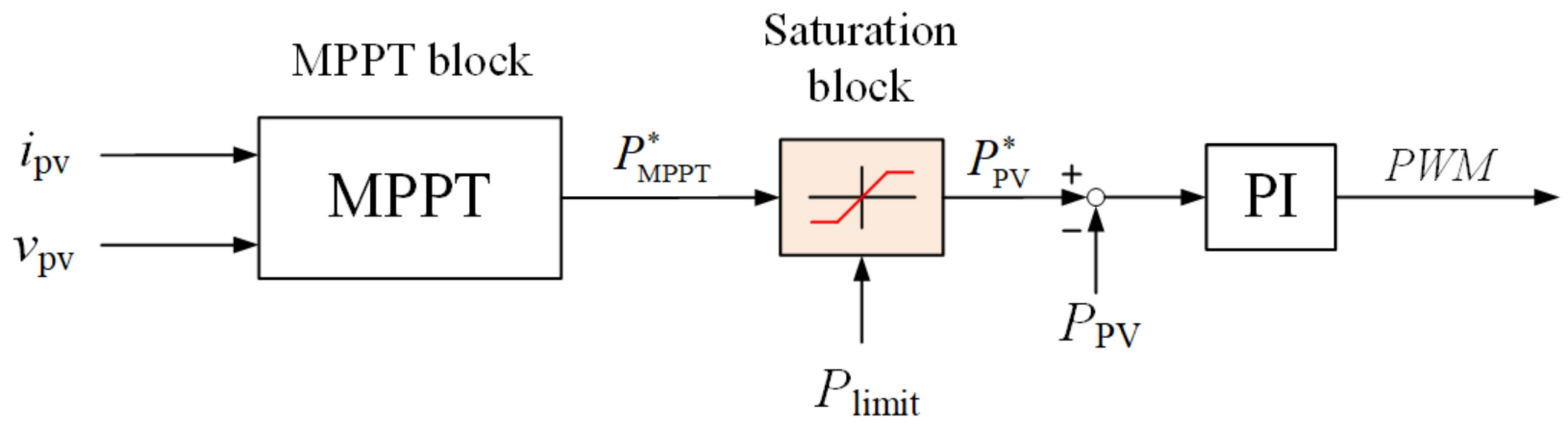

(a)

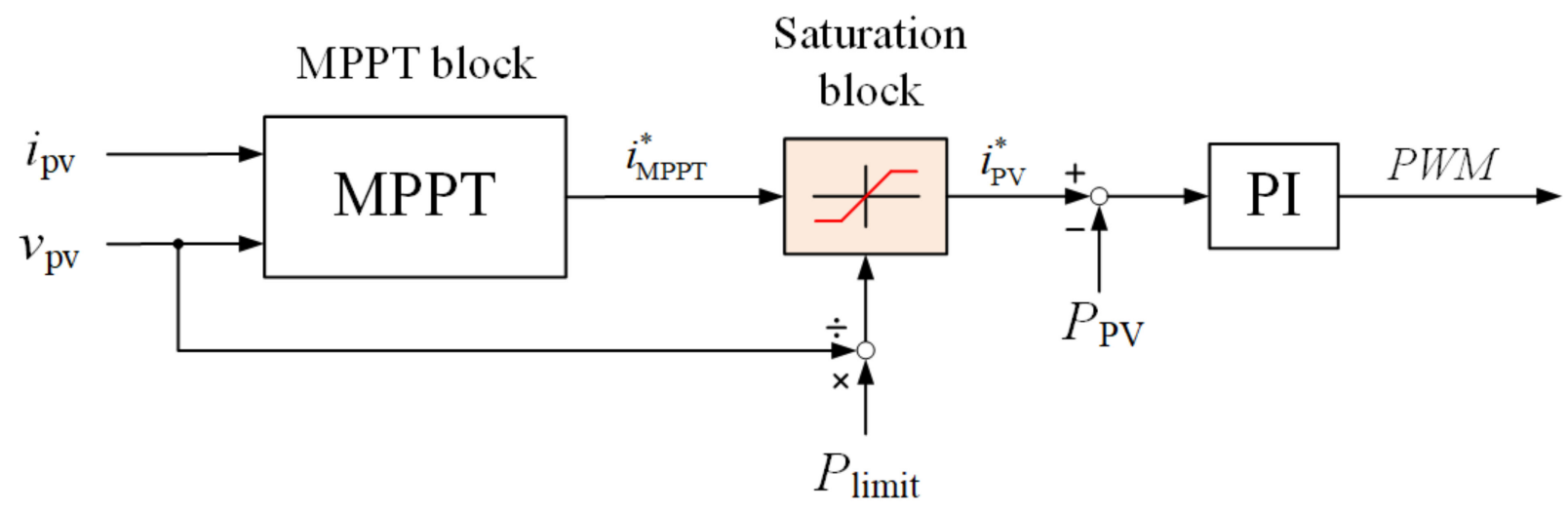

(b)

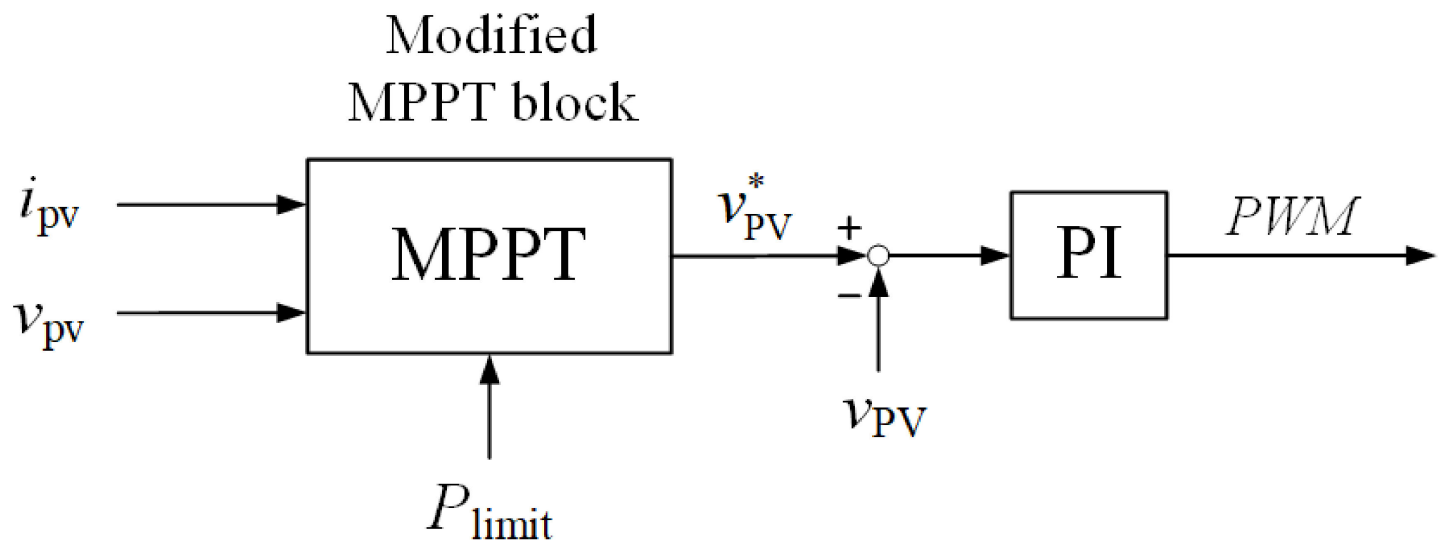

(c)

Figure 8. Control structures of different power-limiting strategies. (a) Direct power control [53]. (b) Current-limiting control [54]. (c) Modified MPPT strategy [55].

The principle of the three approaches can be summarized as: when the power reference $p_{\mathrm{mpp}}^{*}$ from MPPT algorithm is below the power limit $\left(P_{\text {limit }}\right)$, the PV systems will work in MPPT mode; when the available PV power $p_{\text {mpp }}^{*}$ exceeds $P_{\text {limit }}$, the PV output power will be maintained constant (i.e., $P_{\mathrm{pv}}^{*}=P_{\text {limit }}$ ). It should be noted that there are two operation points corresponding to the same power, which, respectively, are located at the left side 
and right side in the curve of PV power-voltage characteristics. Therefore, the PV voltage reference $v_{\mathrm{pv}}^{*}$ based on modified MPPT strategy can be expressed as:

$$
v_{\mathrm{pv}}^{*}=\left\{\begin{array}{cc}
v_{\mathrm{mpp}}^{*} & {\left[p_{\mathrm{mpp}}^{*} \leq P_{\text {limit }}\right.} \\
v_{\mathrm{pv}} \mp v_{\text {step }} & {\left[p_{\mathrm{mpp}}^{*}>P_{\text {limit }}\right.}
\end{array}\right]
$$

where $v_{\mathrm{mpp}}^{*}$ is the output voltage provided by the MPPT algorithm, and $v_{\text {step }}$ is the perturbation voltage as defined before. When PV systems work at the left side of MPP, the $\mathrm{PV}$ voltage should subtract the perturbation size (i.e., $v_{\mathrm{pv}}-v_{\text {step }}$ ). Otherwise, when the operation point is at the right side of MPP, the PV voltage should add the perturbation size, that is, $v_{\mathrm{pv}}+v_{\text {step }}$.

Intuitively, the power-limiting control is the simplest to realize among the three aforementioned power constraints, because it just need a comparison between the constant power limit and the instantaneous PV production. However, maintaining the operating point at the corresponding flexible power point is still a challenge for power-limiting control, where the stability, dynamic, and steady-state response are major concerns, especially under changing environmental conditions. In order to concisely compare the performance of different PLC strategies, a table is made regarding the dynamic responses, tracking errors, and stability, as shown in Table 4 below.

Table 4. A comparison of the PLC strategies [56].

\begin{tabular}{cccc}
\hline Methods & Dynamic Responses & Tracking Errors & Stability \\
\hline Direct power control & fast & small & medium \\
\hline Current-limiting control & fast & small & low \\
\hline Modified MPPT strategy (left) & slow & medium & high \\
\hline Modified MPPT strategy (right) & slow & large & medium \\
\hline
\end{tabular}

It can be seen from Table 4 that the modified MPPT strategy (when operating at the left of MPP) has high robustness and minor tracking error, which makes it a cost-effective way to achieve power-limiting control. On the other hand, direct power control and currentlimiting control have advantages in dynamic response and complexity. If combined with some energy storage technologies, they can obtain superiority in some specific applications.

The PLC will limit the feed-in power of PV systems under a given value. One way to absorb the excessive PV power is to integrate local loads (e.g., domestic appliances) or dummy controllable loads [57]. The configuration of dummy loads integrated into PV systems can be demonstrated in Figure 1b, where the battery is replaced with dummy loads, and a matrix converter is commonly adopted as the DC/DC stage connected to the DC bus. Nevertheless, in this case, the surplus PV power cannot be recycled without being stored but dissipated by the loads, which decreases the utilization of solar energy. Moreover, there is no possibility to apply the redundant PV power to grid support or self-consumption.

In order to improve the utilization of solar energy in PLC mode, the ESS can be integrated for load shifting and self-consumption. In this regard, many researchers focus on maximizing the profits of PV systems [58-60]. Literature [58] proposed a charging strategy for PV-battery switch station, which ensured supply reliability of the battery station and improved the self-consumption of PV systems. This strategy contributed to the service availability and operation profit, which makes it an appealing solution. Literature [59] analysed the profitability of PV systems under different billing scenarios, then designed the best sizing parameters of PV and battery in each case. Therefore, it gives a reference scenario for potential customers of rooftop PV systems and provides advice for PV investment. In [60], a demand side management algorithm was used in a PV-ESS system, where the utilization of PV production on-site can be maximized. This paper helps to create energy-independent buildings and contributes to maximizing the 
economic profit for building users and offers technical benefits for distribution network operators. Furthermore, the effects of self-consumption on grid and PV systems (e.g., grid relief, reliability) have drawn more attention in recent years. Literature [61] compared the grid-relieving effects of several self-consumption strategies, so that the load-shifting can be made based on the PV power supply and load demand. In [62], the impact of the proposed energy management strategy on battery lifespan was investigated in a typical Danish scenario, and the battery degradation under different operation scenarios was analysed based on a battery lifetime model. Therefore, the influence factors on battery lifetime can be represented, which is helpful to develop an energy management algorithm to increase the battery life expectancy as well as the self-consumption. Literature [63] adopted ESS to enhance the reliability of PV inverter with considering some self-consumption strategies. It turned out that the ESS can reduce thermal stress and damage of power devices to some extent, thus obviously improving the reliability of the PV system.

In conclusion, in order to avoid overloading and voltage rise on the distribution network and ensure a secure power supply, it is necessary for it to be equipped with some active power constraint functions. Hence, flexible active power control methods have drawn much attention and been an interesting topic. Specifically, power reserve control can keep a certain amount of power for potential frequency regulation, and the accurate MPP estimation is the most essential task in this control mode. Besides, further research is needed on integrating ESS into PV systems to achieve power reserve control. For power ramp-rate control, it is important to coordinate ESS and PV to limit the ramp rate. In HESS solutions, dispatching power between energy storage elements is still a challenge, in order to achieve a longer system lifetime and lower cost. As for power-limiting control, its challenge is to increase the utilization of solar energy and self-consumption, thus ESSequipped PV systems present several possibilities for research. Control strategies still remain to be further developed to lower the operation cost, while some ancillary service (grid-relieving, lifetime extension) can be considered.

\section{Frequency Regulation Methods}

The main purpose of flexible power control presented in Section 3 is to avoid overloading or instability in distribution networks. Additionally, active power control can also provide one reference for frequency control in case of grid frequency deviations. On the basis of meeting the aforementioned active power constraints, PV power plants must be equipped with frequency support as well. The objective of the frequency control function is to control active power to stabilize grid frequencies when frequency deviations arise in the public power grid. Frequency control functions have been defined in different counties with large proportion of renewable energy [8-11]. As an example, Figure 9 depicts the frequency control curve for PV plants in the Danish grid code [8], where $P_{\text {delta }}$ is the reserve power for providing frequency stabilization (upward regulation) in the case of falling grid frequency. Additionally, the frequency points $f_{1}$ to $f_{4}$ are set to produce different frequency response curves in line with the delivery requirements for the critical power frequency ancillary service. $f_{5}$ and $f_{6}$ are setpoints for final frequency for regulation and final frequency for control, respectively. Droop 1 to droop 4 are droop coefficients in different frequency ranges and stated as a percentage of the plant's nominal output. The parameters can be seen in the signal list for PV plants in [64].

In the prior-art work, the frequency control for PV systems usually emulates the working principle of synchronous generators through virtual synchronous generators (VSG), which act as synchronous inverters and show flexibility and natural friendliness to the power grid [65]. Considering the mechanical inertia and damping loops in synchronous generators, the frequency regulation can be realized generally in two ways, i.e., virtual inertia control (VIC) and frequency-damping control (FDC). By doing this, the inertia and damping of PV systems can be improved correspondingly. Therefore, the frequency control strategies will be reviewed in this section. 


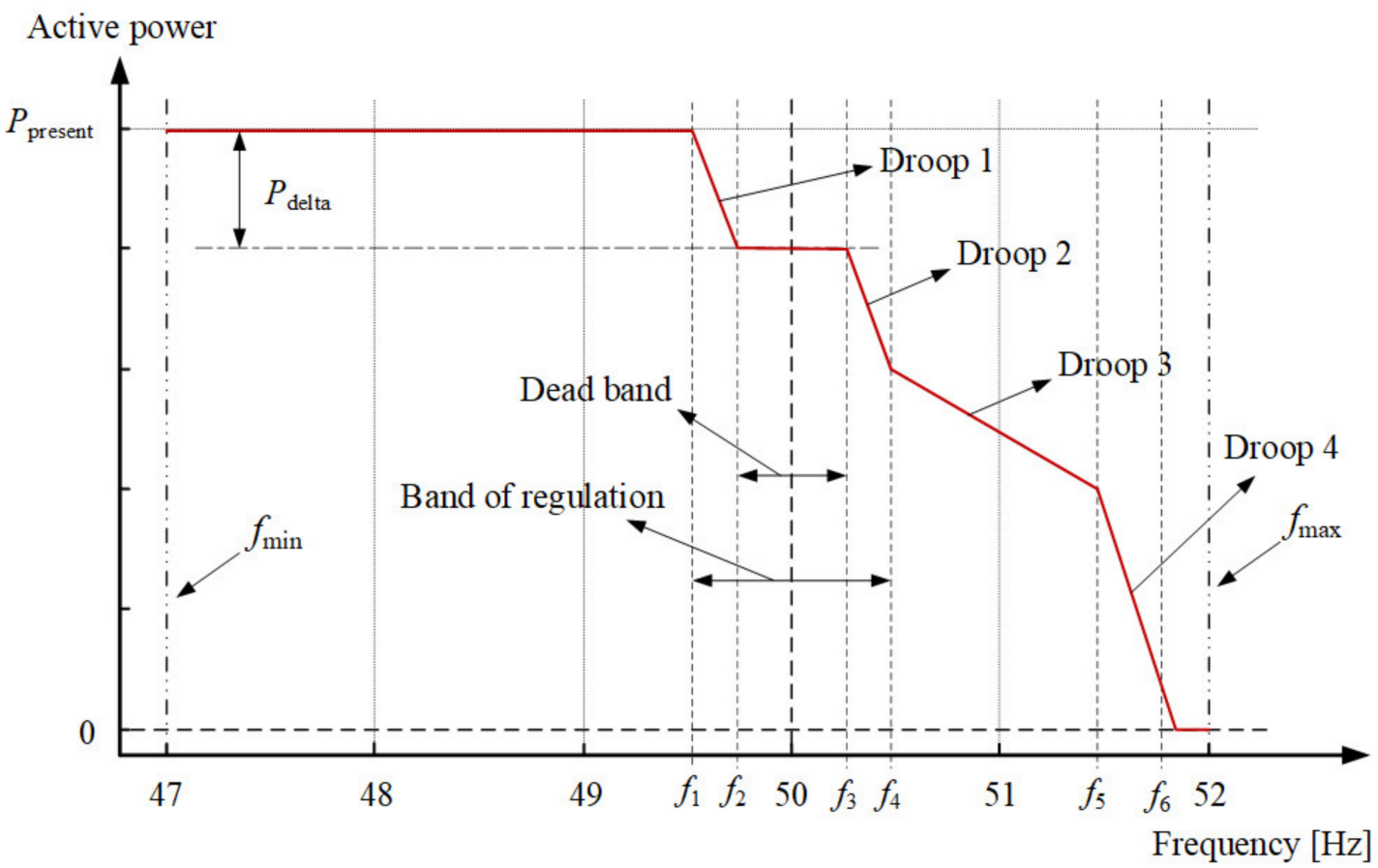

Figure 9. Frequency control curve for PV plants in Danish grid code.

\subsection{Virtual Inertia Control}

Conventionally, the grid frequency is regulated by the SG rotors, where mechanical inertia and damping determine the frequency characteristics. It can be seen from Figure 10 that there are two loops between the power and frequency, i.e., inertia loop and damping loop, which form the swing equation of an SG. Therefore, the swing equation can be expressed as:

$$
\left\{\begin{array}{l}
P_{\mathrm{m}}-P_{\mathrm{e}}=2 H \dot{\omega}+D(\omega-1) \\
\dot{\theta}=\omega-1
\end{array}\right.
$$

where $P_{\mathrm{m}}$ and $P_{\mathrm{e}}$ are the mechanical power and the electro-magnetic power of the SG, respectively, $H$ and $D$ are the inertia constant and damping coefficient, $\omega$ is the angular frequency, $\dot{\omega}$ is the differential of the frequency, and $\theta$ is the internal voltage phase angle of the SG.

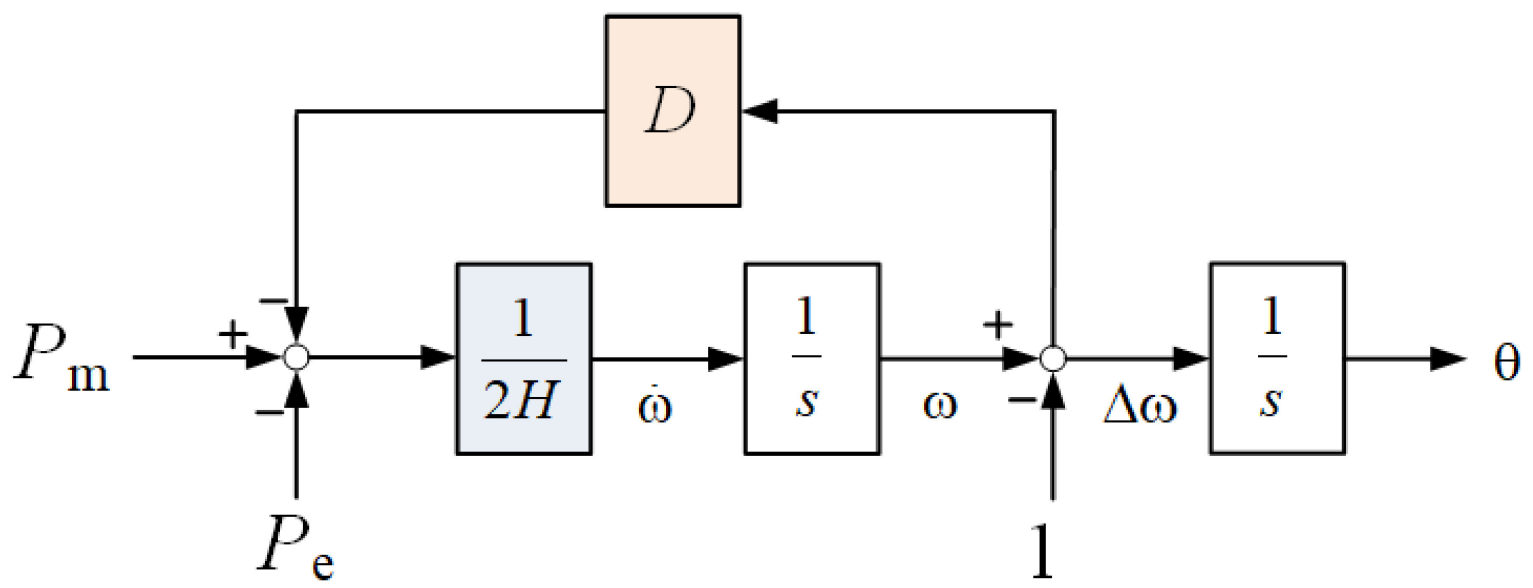

Figure 10. Diagram of the swing equation of SG motors, where $\Delta \omega$ is the angular frequency deviation. 
Virtual inertia control in PV systems can provide inertia support by emulating the inertia loop in SG rotors. Therefore, according to Equation (6), the PV output power should be controlled to proportionate the rate of change of frequency (RoCoF) to achieve the virtual inertia control, i.e.,

$$
P_{\mathrm{VIC}}=2 H_{\mathrm{PV}} \dot{\omega}
$$

where $P_{\mathrm{VIC}}$ is the PV power reference for the VIC and $H_{\mathrm{pv}}$ is the virtual inertia provided by the PV system.

The virtual inertia that PV systems can provide is constrained by the available power for frequency regulation as well as the RoCoF threshold defined by grid codes, i.e.,

$$
\left\{\begin{array}{l}
H_{\text {PV_max }}=\frac{P_{\text {VIC } \max }}{2 \dot{\omega}_{t}} \\
H_{\text {PV_min }}=0
\end{array}\right.
$$

where $H_{\mathrm{PV} \_ \text {max }}$ and $H_{\mathrm{PV} \_ \text {min }}$ are the upper and lower bounds of $H_{\mathrm{PV}}, \dot{\omega}_{t}$ is the RoCoF threshold set by the system operator, and $P_{\text {VIC_max }}$ is the available power that the PV system provides for VIC.

In prior-art work, various inertia control methods were proposed for PV systems, which can be generally classified into methods without energy storage units and with energy storage units [66-71]. In [66], an inertia-based regulation strategy was proposed without energy storage for grid frequency support. In this method, reserved power by modifying the MPPT algorithm has been used to regulate the frequency when there is a mismatch between power supply and demand, thus the stability of frequency can be improved. Nonetheless, due to the insufficient capacity of reserved power by a residential PV system, the grid frequency can only be regulated to a very small extent. In [67], smart loads (i.e., voltage-dependent noncritical loads) were used to enable grid inertia support. By regulating the voltage and power consumption of the noncritical loads, which are integrated through power converters, the grid voltage and frequency can be eventually regulated. Apparently, a lot of communication was need between the system operators and residential loads (e.g., electric heating, lighting, and cooling machines), which improved the cost and decreased the performance of the loads.

In real-life applications, energy storage systems are widely used to improve the inertia and regulate the frequency of the point of connection. In PV-ESS systems with virtual inertia control, the PV arrays and ESS can be integrated in AC-parallel integration or DCparallel integration in Figure 1. Table 5 concludes the commonly used ESS in virtual inertia control in PV systems, including DC link capacitor [68], supercapacitor [69], battery [70], and flywheel [71].

Table 5. A comparison of the ESS-based inertia support strategies.

\begin{tabular}{ccc}
\hline Methods & Advantages & Disadvantages \\
\hline DC-link capacitor [68] & $\begin{array}{c}\text { Without additional investment } \\
\text { Simplicity } \\
\text { Great numbers }\end{array}$ & $\begin{array}{c}\text { Limited by the operation condition of the } \\
\text { converter }\end{array}$ \\
\hline Supercapacitor [69] & $\begin{array}{c}\text { High power density } \\
\text { Long lifetime } \\
\text { Fast dynamics }\end{array}$ & $\begin{array}{c}\text { Small capacity } \\
\text { High cost }\end{array}$ \\
\hline Battery [70] & $\begin{array}{c}\text { Large capacity } \\
\text { High energy density }\end{array}$ & $\begin{array}{c}\text { Real-time RoCoF measurement required } \\
\text { Potential instability concern }\end{array}$ \\
\hline Flywheel [71] & $\begin{array}{c}\text { High power density } \\
\text { Long lifetime }\end{array}$ & High cost \\
& Easy control for inertia emulation & Difficult operation
\end{tabular}

It can be seen form Table 5 that DC-link capacitors are the most common and cheapest solution among various types of ESS due to their great numbers in power converters. 
However, they are limited in a certain range to avoid over modulation, and this method can only be used in the cases in which DC-link voltage can be changed. In contrast, flywheels have a much higher cost, and they can store kinetic energy, which means the inertia emulation can be easily realized through regulating the rotating speed. As for batteries and supercapacitors, they have opposite characteristics in power density and energy density, which means they can complement each other. Combining different energy storage technologies in consideration of their characteristics, HESS can be formed in inertia emulation applications. In this regard, [72] proposed a power management strategy for virtual synchronous generators with a hybrid battery/supercapacitor ESS integrated. When the system frequency was disturbed (e.g., by changing loads), the supercapacitor dealt with the transient power impulses and the battery tackled the power fluctuations with slow dynamics.

\subsection{Frequency-Damping Control}

From Figure 10 and Equation (6), the frequency-damping control needs to emulate the damping loop of a SG. Therefore, in order to realize the frequency-damping control, the PV output power should be controlled to proportionate the frequency deviation, i.e.,

$$
P_{\mathrm{FDC}}=D_{\mathrm{PV}} \Delta \omega
$$

where $P_{\mathrm{FDC}}$ is the $\mathrm{PV}$ power reference for the frequency-damping control, and $D_{\mathrm{PV}}$ is the damping that the PV system provides. Accordingly, the damping that PV systems can provide is constrained by the available power for frequency regulation and the frequency deviation threshold according to the grid code, which can be expressed as:

$$
\left\{\begin{array}{l}
D_{\text {PV_max }}=\frac{P_{\mathrm{FDC} \_ \text {max }}}{\Delta \boldsymbol{\omega}_{t}} \\
D_{\text {PV_min }}=0
\end{array}\right.
$$

where $D_{\mathrm{PV} \_ \text {max }}$ and $D_{\mathrm{PV} \_ \text {min }}$ are the upper and lower bounds of $D_{\mathrm{PV}}, \Delta \omega_{t}$ is the steady-state frequency deviation threshold set by the system operator, and $P_{\text {FDC_max }}$ is the available power that the PV system provides for the frequency-damping method.

In prior-art work, most literature adopted droop control to realize the frequency damping due to its simplicity. The frequency droop characteristics are shown in Figure 11, where $f$ is the frequency of the grid, $f_{\mathrm{L}}$ is the lower limit of the frequency dead zone, $f_{\mathrm{H}}$ is the upper limit, and $f_{\min }$ and $f_{\max }$ are lower and upper frequency limit of system trip, respectively. The dead zone is a range that grid frequency fluctuates without any control intervention, and when the frequency exceeds the dead zone, the PV station will produce an active power output change, which is proportional to the frequency deviation. In this regard, a control strategy of the PV system was developed in [73] to participate in grid frequency regulation. In this paper, a certain reserve was kept through PV power curtailment, so that the PV power could regulate the grid frequency by increasing or reducing a certain amount of output power according to the frequency deviation. This strategy limited the frequency recovery speed, so that the unfavourable disturbance to the system can be reduced, which improved the grid stability. In [74], a decentralized frequency regulation strategy for PV plants was proposed based on droop control. After the system frequency changes, each PV power unit calculates the active power adjustment amount according to the frequency regulation coefficient and then adds the power change to the PV unit active power control system. Therefore, the response time can be reduced, since each PV unit can achieve frequency regulation directly through the change in terminal frequency value, which makes full use of the fast adjustment of their own active power. Ref. [75] discussed the disadvantages of conventional droop control of PV and energy storage-based microgrids and proposed an improved frequency adjustment strategy based on feedforward power, whose control diagram is shown in Figure 12. In this diagram, * represent reference values, and $\mathrm{P}^{\prime}, \mathrm{Q}^{\prime}$ are feedforward power provided by $\mathrm{PQ}$ calculation through a high-pass filter. $\mathrm{R}$ and $\mathrm{K}$ are droop coefficients of $\mathrm{P}-f$ and $\mathrm{Q}-\mathrm{U}$, respectively. It can 
be seen from Figure 12 that the additional virtual inertial link can regulate the response time by changing the inertia time constant, thus slowing down the transition process in power fluctuation. In addition, the power feedback can quickly detect the load disturbance and obtain the power compensation instructions. Therefore, a steady transition and recovery process can be ensured; hence, the frequency stability can be improved.

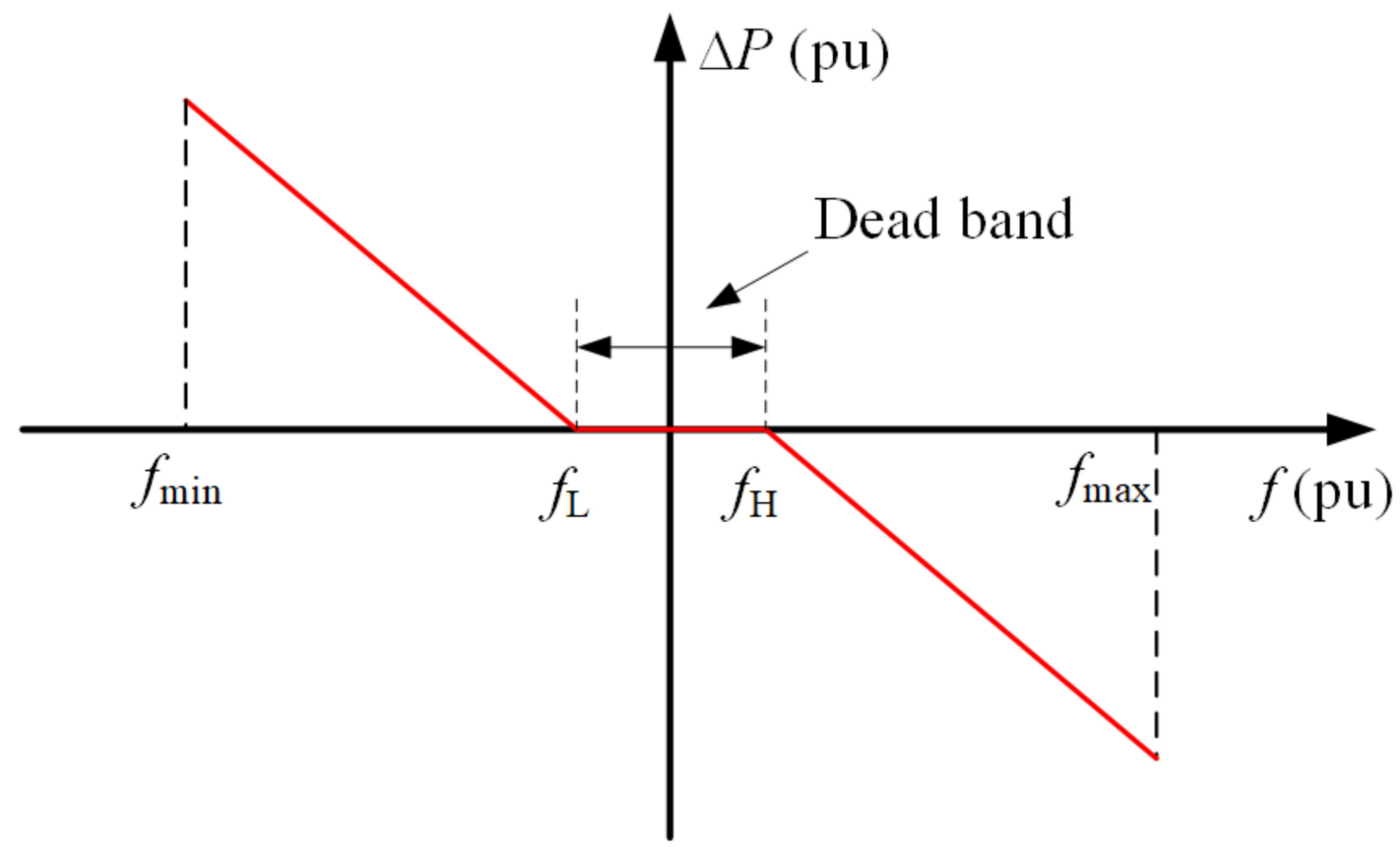

Figure 11. The frequency droop characteristic in droop control mode.

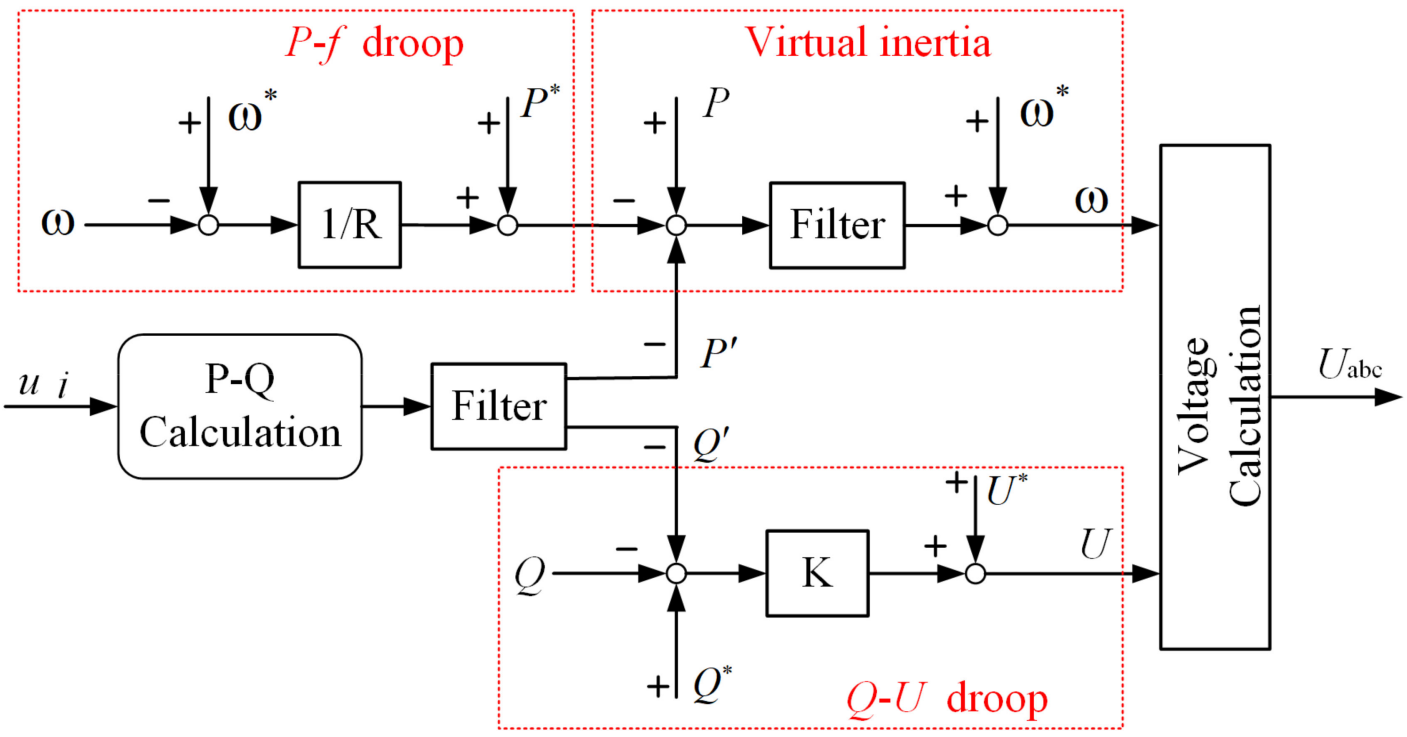

Figure 12. The control diagram in [75].

In order to improve the performance (e.g., dynamics) of PV systems in supporting the grid frequency, some new frequency-damping methods have been proposed. For example, an adaptive strategy, which provides a fast transient response, was proposed in [76], where an estimation method of variation of frequency was adopted, taking into consideration the correlation linking system frequency variation. Ref. [77] adopted a fuzzy-based control strategy for PV systems to regulate frequency without energy storage. In this method, the frequency deviation and changing inertia were used as the inputs of the fuzzy controller, 
whose output determined the operation of the PV systems; thus, the reserved power was used to support the grid frequency. In [78], a nonlinear control algorithm was proposed to adjust the voltage and frequency of PV systems to their nominal values. In this method, the frequency regulator consisted of two sub-modules, where one sub-module modified the reference of another sub-module when the frequency deviation occurred. By doing this, the transient performance of PV systems can be improved. Ref. [79] proposed an active power control strategy based on the combined power-frequency droop characteristics to support the grid frequency, as shown in Figure 13. The active power output is determined using P-f droop control; the slow frequency control deals with load-frequency control, and the fast frequency control deals with the inertial response. Therefore, the developed control strategy can provide proper active power in light of the predetermined characteristics without affecting each other.

Recently, it has been a trend to combine virtual inertia control and the frequencydamping method in PV systems to support the grid frequency. In this regard, [80] proposed a coordination strategy of VIC and FDC for optimal frequency support. The control structure of this method is shown as Figure 14. It can be seen from Figure 14 that the input of the PI controller can be obtained from the available PV power, the reserved power, and the additional reference introduced by VIC and FDC. Through the PI controller, the duty cycle will be generated to control the converter. This method can maximize the power regulation capability, which is a cost-effective solution to enhance the stability of the grid frequency. In [81], the impact of ESS on the frequency stability of the grid was discussed, where the virtual inertia control was used for inertia response, and the droop control was used for primary frequency response. The control structure is shown in Figure 15. It proved that implementing virtual inertia control with ESS can support the frequency, emulating inherent inertia and frequency-damping control in different timescales.

For the VIC and FDC, respectively.

In conclusion, by emulating the control loops of synchronous generators, two frequency regulation methods can be formed, i.e., virtual inertia control and frequencydamping control. For virtual control, ESS is widely integrated into PV systems to provide virtual inertia for frequency regulation, and it is an interesting topic to combine different energy storage elements to achieve virtual inertia control in a more flexible way. As for frequency-damping control, the droop control is widely used in most cases. Considering the response time, some improved methods (e.g., fuzzy control) have been proposed, which shows better performance than droop control. Recently, it has been a trend to combine virtual inertia control and frequency-damping control for grid frequency regulation, which can function in different timescales and shows a better performance than a single method.

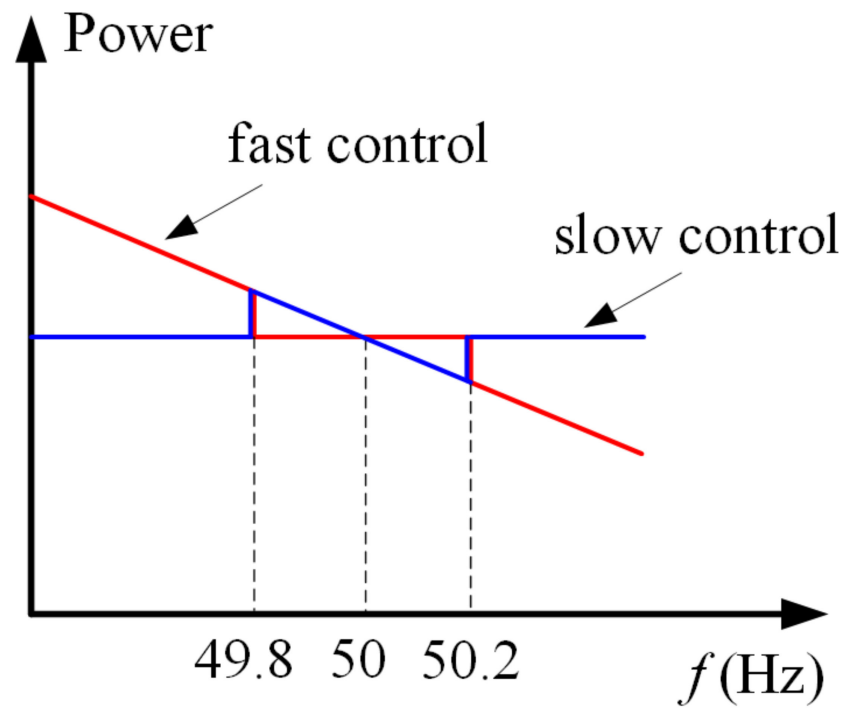

Figure 13. Combine P-f droop characteristics in [79]. 


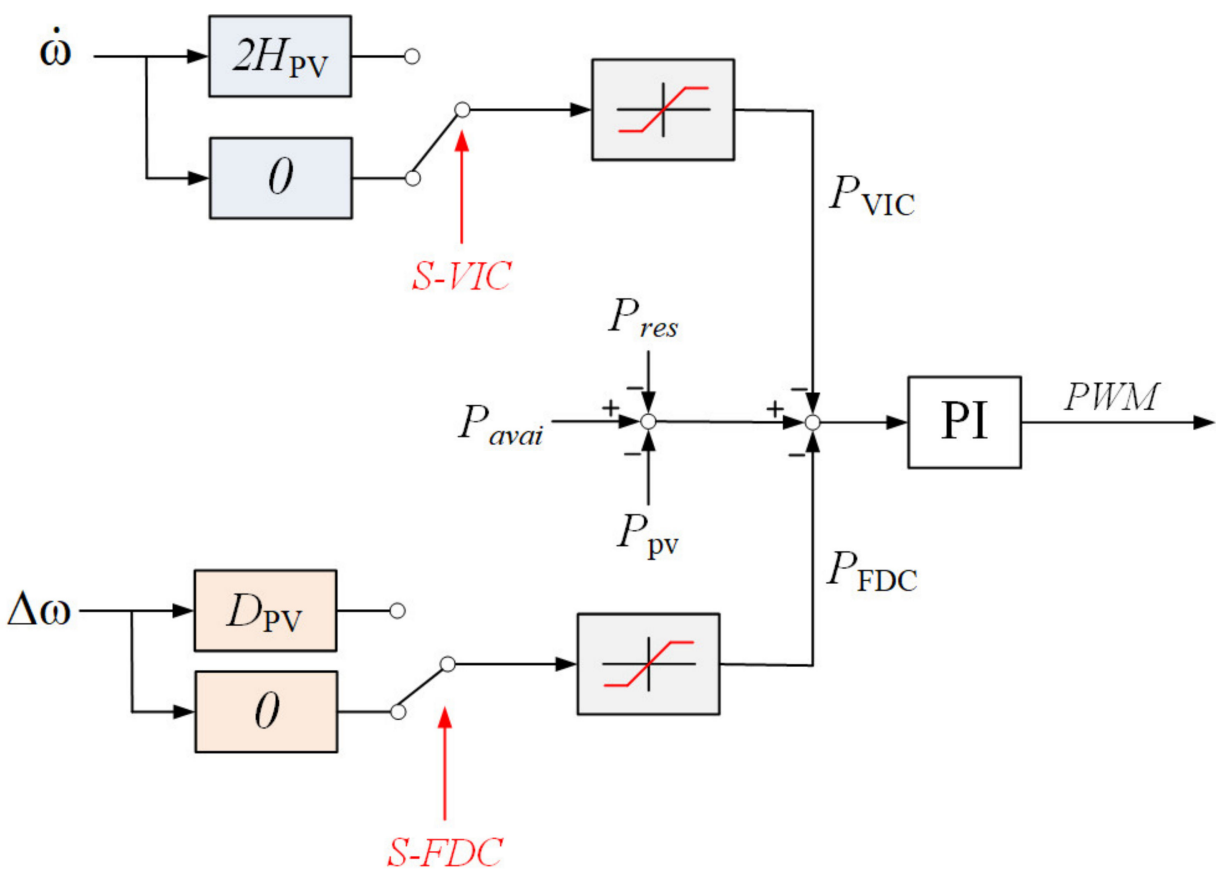

Figure 14. Control diagram in [80], where S-VIC and S-FDC are the switching signals.

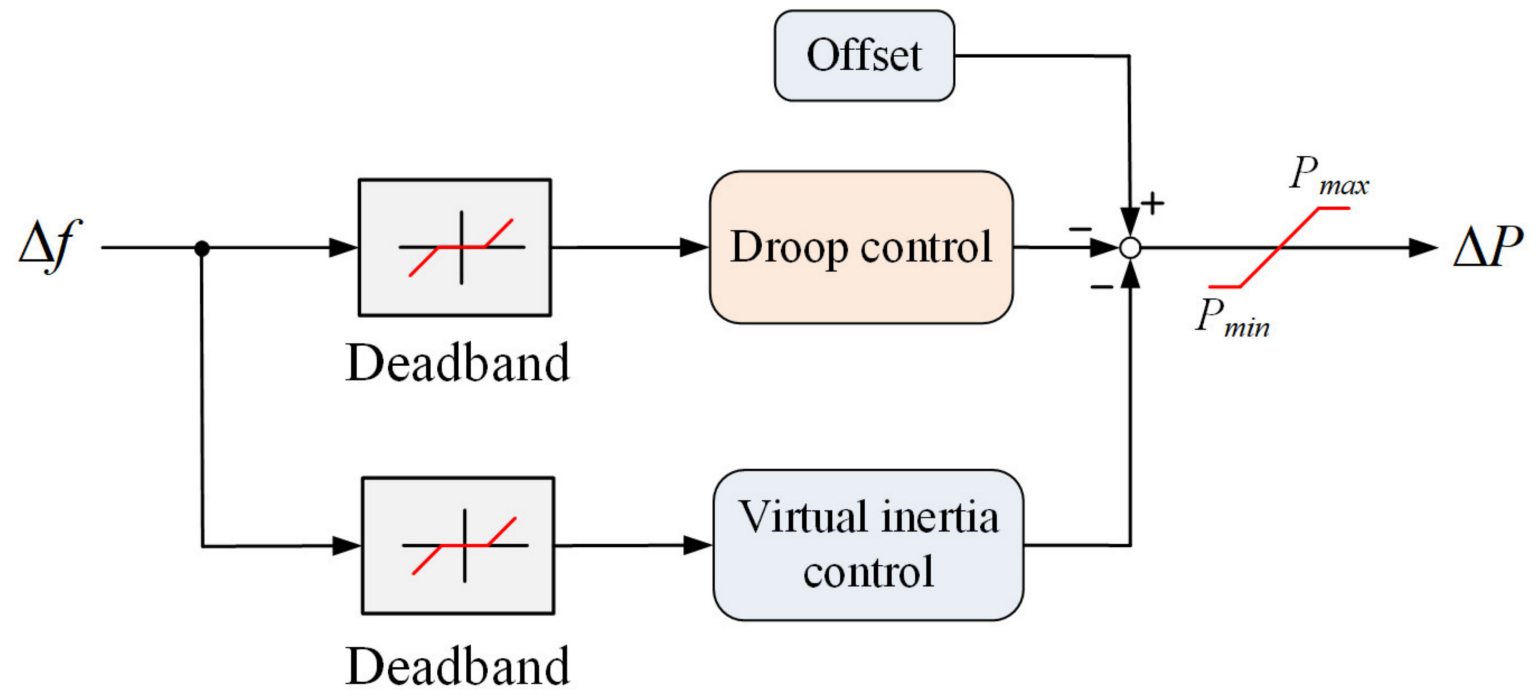

Figure 15. Control diagram in [81].

\section{Conclusions}

A review of the flexible active power control based on PV-ESS systems was presented in this paper. Firstly, the topologies of PV-ESS integration were classified, and their advantages and applications were discussed subsequently. Integrating ESS into multiport converters is an interesting direction, where the power density and efficiency can be improved. Nonetheless, proper control strategies are the main challenge. In addition, lowering the cost of PV systems in residential and commercial applications is always an important aim. Considering the efficiency, cycle life, price, and capacity of different energy storage technologies, a hybrid ESS is more cost effective than a single ESS. Hybrid ESS still remains a hot topic with a lot of research to be carried out in the future.

Furthermore, this paper also introduced the active power constraints in different countries, continuing with the review and comparison of several active power control strategies (i.e., power reserve control, power ramp-rate control, and power-limiting control). 
Given that these control strategies are based on power retrenchment, which cannot supply additional active power to the grid during certain scenarios, an ESS needs to be integrated for effective grid support. At present, the studies about flexible active power control methods based on PV-ESS are insufficient. Specifically, (1) the coordinated strategies of PV and ESS need to be further developed to meet the grid requirements and to enable grid-friendly systems. (2) Hybrid ESS can be further explored considering the cost and ancillary services (e.g., self-consumption) to make the PV-ESS systems more profitable. Therefore, to integrate the PV systems into the grid in a flexible and cost-effective way is still a major challenge.

On the basis of active power constraints, some frequency regulation methods were reviewed. Inspired by the characteristics of synchronous generators, which regulate the grid frequency through the inertia loop and damping loop. Accordingly, the frequency control of the grid with the support of PV systems can be realized through virtual inertia control and frequency-damping control. In virtual inertia control, various energy storage unit have been integrated into PV systems according to specific applications. Recently, hybrid ESS became a promising solution for virtual inertia control due to its cost effectiveness. As for frequency-damping control, droop controller are used in most applications. Considering some nonlinear components in PV systems, a few novel control methods (e.g., nonlinear control) are adopted to enhance the stability and improve the dynamic response of the frequency. In addition, a combination of virtual inertia control and frequency-damping control has become a trend to achieve fast and reliable grid frequency support both in shortand long-term events.

Author Contributions: Conceptualization, X.W. and T.K.; investigation, X.W.; methodology, X.W. and T.K.; writing—original draft, X.W.; writing—review and editing, X.W. and T.K.; supervision, T.K. All authors have read and agreed to the published version of the manuscript.

Funding: The authors acknowledge the support of China Scholarship Council (CSC).

Institutional Review Board Statement: Not applicable.

Informed Consent Statement: Not applicable.

Data Availability Statement: Not applicable.

Conflicts of Interest: The authors declare no conflict of interest.

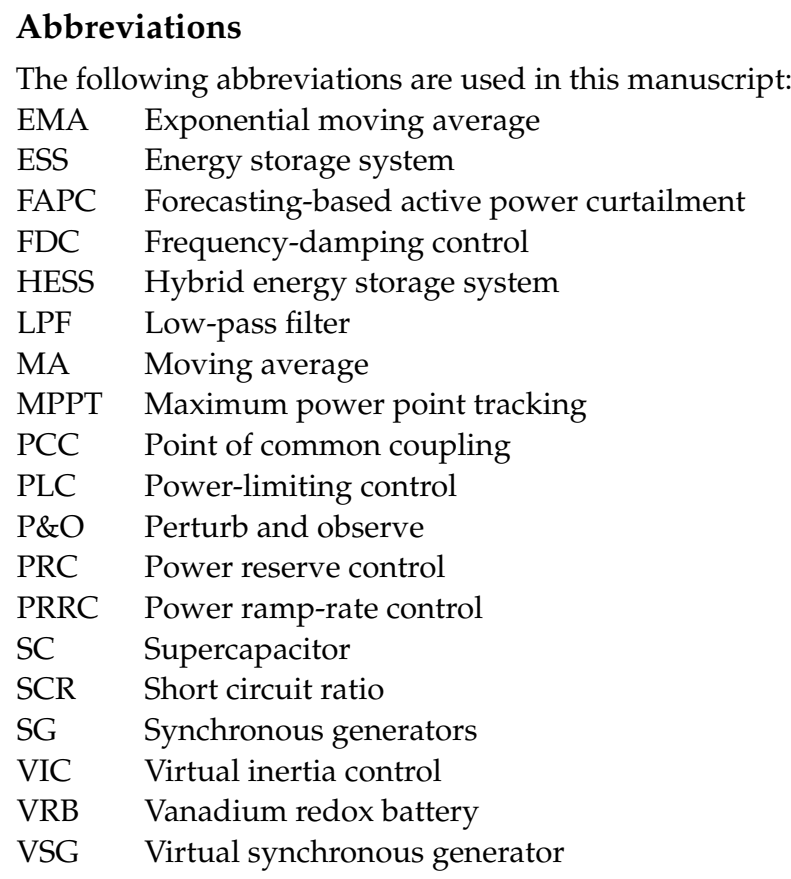




\section{References}

1. Renewables 2021-Global Status Report. Available online: https:/ / www.ren21.net/ (accessed on 15 June 2021).

2. Yang, Y.; Enjeti, P.; Blaabjerg, F.; Wang, H. Wide-Scale Adoption of Photovoltaic Energy: Grid Code Modifications Are Explored in the Distribution Grid. IEEE Ind. Appl. Mag. 2015, 21, 21-31. [CrossRef]

3. Shivashankar, S.; Mekhilef, S.; Mokhlis, H.; Karimi, M. Mitigating Methods of Power Fluctuation of Photovoltaic Sources-A Review. Renew. Sustain. Energy Rev. 2016, 59, 1170-1184. [CrossRef]

4. Xu, J.; Bian, S.; Liu, M.; Zhang, Z.; Xie, S. Stability Analysis of Grid-Connected Inverters during the Transient of Grid Voltage Fluctuations in Weak Grid Cases. In Proceedings of the 2019 IEEE Energy Conversion Congress and Exposition (ECCE), Baltimore, MD, USA, 29 September-3 October 2019; pp. 5185-5190.

5. Stetz, T.; Appen, J.; Niedermeyer, F.; Scheibner, G.; Sikora, R.; Braun, M. Twilight of the Grids: The Impact of Distributed Solar on Germany's Energy Transition. IEEE Power Energy Mag. 2015, 13, 50-61.

6. Woyte, A.; Thong, V.; Belmans, R.; Nijs, J. Voltage Fluctuations on Distribution Level Introduced by Photovoltaic Systems. IEEE Trans. Energy Conver. 2006, 21, 202-209. [CrossRef]

7. Fang, J.; Li, H.; Tang, Y.; Blaabjerg, F. On the Inertia of Future More-Electronics Power Systems. IEEE J. Emerg. Sel. Top. Power Electron. 2019, 7, 2130-2146. [CrossRef]

8. Technical Regulation 3.2.2 for PV Power Plants with a Power Output above 11 kW; Energinet: Fredericia, Denmark, 2016.

9. Technical Guideline-For Power Generating Units, Systems and Storage Systems as Well as for Their Components. Germany Grid Codes; Fördergesellschaft Windenergie und andere Dezentrale Energien: Berlin, Germany, 2019. Available online: https://wind-fgw.de/ wp-content/uploads/2019/05/TG_Part8_Rev9_EN_preview.pdf (accessed on 29 October 2021).

10. Australian Grid Code-National Electricity Rules Version 139. Available online: https://www.aemc.gov.au/sites/default/files/ 2020-05/NER\%20v139\%20full_1.pdf (accessed on 20 May 2020).

11. Residential Grid-Connected Photovoltaic (PV) System; China Photovoltaic Industry Association: Beijing, China, 2019.

12. Sangwongwanich, A.; Yang, Y.; Blaabjerg, F.; Sera, D. Delta Power Control Strategy for Multistring Grid-Connected PV Inverters. IEEE Trans. Ind. Appl. 2017, 53, 3862-3870. [CrossRef]

13. Sangwongwanich, A.; Yang, Y.; Blaabjerg, F. A Cost-Effective Power Ramp-Rate Control Strategy for Single-Phase Two-Stage Grid-Connected Photovoltaic Systems. In Proceedings of the 2016 IEEE Energy Conversion Congress and Exposition (ECCE), Milwaukee, WI, USA, 18-22 September 2016; pp. 1-7.

14. Yang, Y.; Blaabjerg, F.; Wang, H. Constant Power Generation of Photovoltaic Systems Considering the Distributed Grid Capacity. In Proceedings of the 2014 IEEE Applied Power Electronics Conference and Exposition(APEC), Fort Worth, TX, USA, 16-20 March 2014; pp. 379-385.

15. Kouro, S.; Leon, J.I.; Vinnikov, D.; Franquelo, L.G. Grid-Connected Photovoltaic Systems: An Overview of Recent Research and Emerging PV Converter Technology. IEEE Ind. Electron. Mag. 2015, 9, 47-61. [CrossRef]

16. Indu Rani, B.; Saravana Ilango, G.; Nagamani, C. Control Strategy for Power Flow Management in a PV System Supplying DC Loads. IEEE Trans. Ind. Electron. 2013, 60, 3185-3194. [CrossRef]

17. Chiang, S.J.; Chang, K.T.; Yen, C.Y. Residential Photovoltaic Energy Storage System. IEEE Trans. Ind. Electron. 1998, 45, 385-394. [CrossRef]

18. Kim, N.; Parkhideh, B. Ramp-Rate Control Strategy for Distributed PV-ESS AC-Stacked Inverter Architecture. In Proceedings of the 2017 IEEE 8th International Symposium on Power Electronics for Distributed Generation Systems (PEDG), Florianopolis, Brazil, 17-20 April 2017; pp. 1-6.

19. Kim, N.; Roy, C.; Parkhideh, B. A Single-Stage Capacitor-Bridge Boost Converter Topology for PV-Battery Series Integration in Regulated DC Microgrids. In Proceedings of the 2021 IEEE Applied Power Electronics Conference and Exposition (APEC), Phoenix, AZ, USA, 14-17 June 2021; pp. 2613-2619.

20. Wang, Z.; Zhang, H.; He, B. Circuit Structure and Control Method of a Novel PV Energy Storage System. Guangdong Electr. Power 2020, 8, 1-8.

21. Pullaguram, D.; Mudaliyar, S.R.; Mishra, S.; Senroy, N. Isolated PV Battery Management System to Power Home Appliances. In Proceedings of the 2017 7th International Conference on Power Systems (ICPS), Pune, India, 21-23 December 2017; pp. 755-760.

22. Yong, H.; Li, X.; Wu, X.; Li, M.; Wang, Y. Stability Control Design for TAB-Based Three-Port Bidirectional DC/DC Converters in PV-Battery Grid-Connected Applications. In Proceedings of the IECON 2020 the 46th Annual Conference of the IEEE Industrial Electronics Society, Singapore, 18-21 October 2020; pp. 3469-3474.

23. Showers, S.O.; Raji, A.K. Benefits and Challenges of Energy Storage Technologies in High Penetration Renewable Energy Power Systems. In Proceedings of the 2019 IEEE PES/IAS Power Africa, Abuja, Nigeria, 20-23 August 2019; pp. $209-214$.

24. Lin, D.; Zhao, B.; Li, P.; Wu, X.Z.; Gu, Y.N. Real-Time Fluctuation Smoothing Method for Photovoltaic Power Station Using Lead Carbon Battery. Power Syst. Technol. 2018, 42, 1518-1525.

25. Şahin, M.E.; Blaabjerg, F. A Hybrid PV-Battery/Supercapacitor System and a Basic Active Power Control Proposal in MATLAB/Simulink. Electronics 2020, 9, 129. [CrossRef]

26. Wang, X.; Liu, Y. Analysis of Energy Storage Technology and Their Application for Micro Grid. In Proceedings of the 2017 International Conference on Computer Technology, Electronics and Communication (ICCTEC), Dalian, China, 19-21 December 2017; pp. 972-975. 
27. Lei, C.; Zhang, X.; Han, P. The Capacity Optimization of Hybrid Energy Storage System for Wind Power Smoothing. In Proceedings of the 2014 IEEE International Conference on Mechatronics and Automation, Tianjin, China, 3-6 August 2014; pp. 2106-2110.

28. Jamahori, H.F.; Rahman, H.A. Hybrid Energy Storage System for Life Cycle Improvement. In Proceedings of the 2017 IEEE Conference on Energy Conversion (CENCON), Kuala Lumpur, Malaysia, 30-31 October 2017; pp. 196-200.

29. Lin, X.; Lei, Y. Coordinated Control Strategies for SMES-Battery Hybrid Energy Storage Systems. IEEE Access 2017, 5, 23452-23465.

30. Wang, G.; Ciobotaru, M.; Agelidis, V.G. Power Smoothing of Large Solar PV Plant Using Hybrid Energy Storage. IEEE Trans. Sustain. Energy 2014, 5, 834-842. [CrossRef]

31. Tian, C.; Li, K.; Yan, Y.; Zhang, C. A Multi-Time Scale Control Strategy of Hybrid Energy Storage System in Wind Farm Based on Empirical Mode Decomposition. Power Syst. Technol. 2015, 39, 2167-2172.

32. Jing, W.; Lai, C.H.; Wong, S.H.; Wong, M.L. Battery-Supercapacitor Hybrid Energy Storage System in Standalone DC Microgrids: A Review. IET Renew. Power Gener. 2017, 11, 461-469. [CrossRef]

33. Jing, W.L.; Lai, C.H.; Wong, W.S.H.; Wong, M.L.D. Cost Analysis of Battery-Supercapacitor Hybrid Energy Storage System for Standalone PV Systems. In Proceedings of the 4th IET Clean Energy and Technology Conference (CEAT 2016), Kuala Lumpur, Malaysia, 14-15 November 2016; pp. 1-6.

34. Roy, P.; He, J.; Liao, Y. Cost Minimization of Battery-Supercapacitor Hybrid Energy Storage for Hourly Dispatching Wind-Solar Hybrid Power System. IEEE Access 2020, 8, 210099-210115. [CrossRef]

35. Batzelis, E.I.; Kampitsis, G.E.; Papathanassiou, S.A. Power Reserves Control for PV Systems with Real-Time MPP Estimation via Curve Fitting. IEEE Trans. Sustain. Energy 2017, 8, 1269-1280. [CrossRef]

36. Li, X.; Wen, H.; Zhu, Y.; Jiang, L.; Hu, Y.; Xiao, W. A Novel Sensor-less Photovoltaic Power Reserve Control with Simple Real-Time MPP Estimation. IEEE Trans. Power Electron. 2019, 34, 7521-7531. [CrossRef]

37. Scolari, E.; Sossan, F.; Paolone, M. Photovoltaic-Model-Based Solar Irradiance Estimators: Performance Comparison and Application to Maximum Power Forecasting. IEEE Trans. Sustain. Energy 2018, 9, 35-44. [CrossRef]

38. Sangwongwanich, A.; Yang, Y.; Blaabjerg, F. A Sensorless Power Reserve Control Strategy for Two-Stage Grid-Connected PV Systems. IEEE Trans. Power Electron. 2017, 32, 8559-8569. [CrossRef]

39. Peng, Q.; Tang, Z.; Yang, Y.; Blaabjerg, F. Event-Triggering Power Reserve Control for Grid-Connected PV Systems. In Proceedings of the 2020 IEEE Applied Power Electronics Conference and Exposition (APEC), New Orleans, LA, USA, 15-19 March 2020; pp. $417-423$.

40. Serban, I.; Marinescu, C. Flexible Solution for Grid-Connected Operation of Microgrids, Based on a Leading Inverter with Supercapacitor Energy Storage. In Proceedings of the 2018 IEEE International Energy Conference (ENERGYCON), Limassol, Cyprus, 3-7 June 2018; pp. 1-6.

41. Garozzo, D.; Tina, G.M. Evaluation of the Effective Active Power Reserve for Fast Frequency Response of PV with BESS Inverters Considering Reactive Power Control. Energies 2020, 13, 3437. [CrossRef]

42. Sarojini, R.K.; Palanisamy, K.; Sanjeevikumar, P.; Nielsen, J.B. Inertia Emulation Control Technique Based Frequency Control of Grid-Connected Single-Phase Rooftop Photovoltaic System with Battery and Supercapacitor. IET Renew. Power Gener. 2020, 14, 1156-1163.

43. Chen, X.; Du, Y.; Wen, H.; Jiang, L.; Xiao, W. Forecasting-Based Power Ramp-Rate Control Strategies for Utility-Scale PV Systems. IEEE Trans. Ind. Electron. 2019, 66, 1862-1871.

44. Hund, T.D.; Gonzalez, S.; Barrett, K. Grid-tied PV system energy smoothing. In Proceedings of the 2010 35th IEEE Photovoltaic Specialists Conference, Honolulu, HI, USA, 20-25 June 2010; pp. 2762-2766.

45. Wilson, A.R. Event Triggered Analog Data Acquisition Using the Exponential Moving Average. IEEE Sens. J. 2014, 14, $2048-2055$.

46. Koiwa, K.; Liu, K.; Tamura, J. Analysis and Design of Filters for the Energy Storage System: Optimal Tradeoff between Frequency Guarantee and Energy Capacity/Power Rating. IEEE Trans. Ind. Electron. 2018, 65, 6560-6570.

47. Kazemi, M.V.; Sadati, S.J.; Gholamian, S.A. Adaptive Frequency Control Support of a DFIG Based on Second-Order Derivative Controller Using Data-Driven Method. Int. Trans. Elect. Energy Syst. 2020, 30, e12424.

48. Alam, M.J.E.; Muttaqi, K.M.; Sutanto, D. A Novel Approach for Ramp-Rate Control of Solar PV Using Energy Storage to Mitigate Output Fluctuations Caused by Cloud Passing. IEEE Trans. Energy Convers. 2014, 29, 507-518.

49. Tran, V.T.; Islam, M.R.; Sutanto, D.; Muttaqi, K.M. Mitigation of Solar PV Intermittency Using Ramp-Rate Control of Energy Buffer Unit. IEEE Trans. Energy Convers. 2019, 34, 435-445. [CrossRef]

50. Jiang, Y.; Shi, X.; Lau, D.; Wang, D. Integration of Electrochemical Capacitors on Silicon Photovoltaic Modules for Rapid-Response Power Buffering. In Proceedings of the 2017 IEEE 44th Photovoltaic Specialist Conference (PVSC), Washington, DC, USA, 25-30 June 2017; pp. 3220-3223.

51. Zhao, Q.; Xian, L.; Roy, S.; Kong, X.; Khambadkone, A.M. Optimal Control of PV Ramp Rate Using Multiple Energy Storage System. In Proceedings of the 2017 IEEE 3rd International Future Energy Electronics Conference and ECCE Asia (IFEEC 2017-ECCE Asia), Kaohsiung, Taiwan, 3-7 June 2017; pp. 928-931.

52. Alvaro, D.; Arranz, R.; Aguado, J. Sizing and Operation of Hybrid Energy Storage Systems to Perform Ramp-Rate Control in PV Power Plants. Int. J. Electr. Power Energy Syst. 2019, 107, 589-596. [CrossRef]

53. Yang, Y.; Wang, H.; Blaabjerg, F.; Kerekes, T. A Hybrid Power Control Concept for PV Inverters with Reduced Thermal Loading. IEEE Trans. Power Electron. 2014, 29, 6271-6275. [CrossRef] 
54. Urtasun, A.; Sanchis, P.; Marroyo, L. Limiting the Power Generated by a Photovoltaic System. In Proceedings of the 10th International Multi-Conferences on Systems, Signals \& Devices 2013 (SSD13), Hammamet, Tunisia, 18-21 March 2013; pp. 1-6.

55. Sangwongwanich, A.; Yang, Y.; Blaabjerg, F. High-Performance Constant Power Generation in Grid-Connected PV Systems. IEEE Trans. Power Electron. 2016, 31, 1822-1825. [CrossRef]

56. Sangwongwanich, A.; Yang, Y.; Blaabjerg, F.; Wang, H. Benchmarking of Constant Power Generation Strategies for Single-Phase Grid-Connected Photovoltaic Systems. IEEE Trans. Ind. Appl. 2018, 54, 447-457. [CrossRef]

57. Omran, W.A.; Kazerani, M.; Salama, M.M.A. Investigation of Methods for Reduction of Power Fluctuations Generated from Large Grid-Connected Photovoltaic Systems. IEEE Trans. Energy Convers. 2011, 26, 318-327.

58. Liu, N.; Chen, Q.; Lu, X.; Liu, J.; Zhang, J. A Charging Strategy for PV-Based Battery Switch Stations Considering Service Availability and Self-Consumption of PV Energy. IEEE Trans. Ind. Electron. 2015, 62, 4878-4889. [CrossRef]

59. Galilea, C.; Pascual, J.; Berrueta, A.; Ursua, A.; Marroyo, L. Economic Analysis of Residential PV Self-Consumption Systems with Li-ion Batteries Under Different Billing Scenarios. In Proceedings of the 2019 IEEE International Conference on Environment and Electrical Engineering and 2019 IEEE Industrial and Commercial Power Systems Europe (EEEIC/I\&CPS Europe), Genova, Italy, 11-14 June 2019; pp. 1-6.

60. Kelepouris, N.S.; Nousdilis, A.I.; Bouhouras, A.S.; Christoforidis, G.C.; Yerasimou, Y.; Chatzigeorgiou, N.G.; Georghiou, G.E.; Celli, G.; Mocci, S.; Gal, E.; et al. Impact of Demand Side Management on the Self-Sufficiency and Self-Consumption of Buildings with Photovoltaic and Storage Systems. In Proceedings of the 2021 9th International Conference on Modern Power Systems (MPS), Cluj-Napoca, Romania, 16-17 June 2021; pp. 1-6.

61. Moshövel, J.; Kairies, K.; Magnor, D. Analysis of the Maximal Possible Grid Relief from PV-Peak-Power Impacts by Using Storage Systems for Increased Self-Consumption. Appl. Energy 2015, 137, 567-575. [CrossRef]

62. Farinet, D.; Maurer, M.; Vacca, L.; Spataru, S.V.; Stroe, D. Battery Lifetime Analysis for Residential PV-Battery System used to Optimize the Self Consumption-A Danish Scenario. In Proceedings of the 2019 IEEE Energy Conversion Congress and Exposition (ECCE), Baltimore, MD, USA, 29 September-3 October 2019; pp. 6693-6698.

63. Sangwongwanich, A.; Angenendt, G.; Yang, Y.; Sera, D.; Sauer, D.; Blaabjerg, F. Enhancing PV Inverter Reliability with Battery System Control Strategy. CPSS Trans. Power Electron. Appl. 2018, 3, 93-101. [CrossRef]

64. Technical Regulation 3.2.2 Signal List for PV Power Plant; Energinet: Fredericia, Denmark, 2015.

65. Zhou, W.; Xiaosong, Z.; Xufeng, Y.; Wei, X. Review on Virtual Synchronous Generator Technologies. In Proceedings of the 16th IET International Conference on AC and DC Power Transmission (ACDC 2020), Online, 2-3 July 2020; pp. $744-751$.

66. Rajan, R.; Fernandez, F.M. Grid Inertia Based Frequency Regulation Strategy of Photovoltaic System without Energy Storage. In Proceedings of the 2018 International CET Conference on Control, Communication, and Computing (IC4), Thiruvananthapuram, India, 5-7 July 2018; pp. 106-111.

67. Qi, Y.; Yang, T.; Fang, J.; Tang, Y.; Rajashekara, K. Grid Inertia Support Enabled by Smart Loads. IEEE Trans. Power Electron. 2021, 36, 947-957. [CrossRef]

68. Peng, Q.; Fang, J.; Yang, Y.; Liu, T.; Blaabjerg, F. Maximum Virtual Inertia from DC-Link Capacitors Considering System Stability at Voltage Control Timescale. IEEE J. Emerg. Sel. Top. Circuits Syst. 2021, 11, 79-89. [CrossRef]

69. Zhang, R.; Fang, J.; Tang, Y. Inertia Emulation through Supercapacitor Energy Storage Systems. In Proceedings of the 2019 10 th International Conference on Power Electronics and ECCE Asia (ICPE 2019-ECCE Asia), Busan, Korea, 27-30 May 2019; pp. 1365-1370.

70. Suul, J.A.; D'Arco, S.; Guidi, G. Virtual Synchronous Machine-Based Control of a Single-Phase Bi-Directional Battery Charger for Providing Vehicle-to-Grid Services. IEEE Trans. Ind. Appl. 2016, 52, 3234-3244.

71. Yu, J.; Fang, J.; Tang, Y. Inertia Emulation by Flywheel Energy Storage System for Improved Frequency Regulation. In Proceedings of the 2018 IEEE 4th Southern Power Electronics Conference (SPEC), Singapore, 2018, 10-13 December; pp. 1-8.

72. Fang, J.; Li, X.; Tang, Y.; Li, H. Power Management of Virtual Synchronous Generators through Using Hybrid Energy Storage Systems. In Proceedings of the 2018 IEEE Applied Power Electronics Conference and Exposition (APEC), San Antonio, TX, USA, 2018, 4-8 March; pp. 1407-1411.

73. Dajun, J.; Lei, Z.; Dawei, Z.; Ning, C.; Minhui, Q. Research on PV Generation Participating in Power Grid Frequency Regulation. In Proceedings of the 2018 China International Conference on Electricity Distribution (CICED), Tianjin, China, 17-19 September 2018; pp. 1713-1717.

74. Zhao, D.; Qian, M.; Ma, J.; Jiang, D.; Ding, M.; Xiang, L. A Decentralized Frequency Regulation Strategy of PV Power Plant Based on Droop Control. In Proceedings of the 2018 China International Conference on Electricity Distribution (CICED), Tianjin, China, 17-19 September 2018; pp. 1824-1828.

75. Yang, T.; Cui, H.; Zhang, L.; Yang, B.; Li, G.; Lu, Y. Active Frequency Support Control of Energy Storage Power Station Based on Photovoltaic and Energy-Storage Microgrid. In Proceedings of the 2019 IEEE Innovative Smart Grid Technologies-Asia (ISGT Asia), Chengdu, China, 21-24 May 2019; pp. 2362-2367.

76. Meng, J.; Wang, Y.; Fu, C.; Wang, H. Adaptive Virtual Inertia Control of Distributed Generator for Dynamic Frequency Support in Microgrid. In Proceedings of the 2016 IEEE Energy Conversion Congress and Exposition (ECCE), Milwaukee, WI, USA, 18-22 September 2016; pp. 1-5. 
77. Rajan, R.; Fernandez, F.M. Fuzzy Based Control of Grid-Connected Photovoltaic System for Enhancing System Inertial Response. In Proceedings of the 2018 53rd International Universities Power Engineering Conference (UPEC), Glasgow, UK, 4-7 September 2018; pp. 1-6.

78. Okou, A.F.; Akhri, O.; Beguenane, R.; Tarbouchi, M. Nonlinear Control Strategy Insuring Contribution of PV Generator to Voltage and Frequency Regulation. In Proceedings of the 6th IET International Conference on Power Electronics, Machines and Drives (PEMD 2012), Bristol, UK, 27-29 March 2012; pp. 1-5.

79. Kimpara, Y.; Kurimoto, M.; Manabe, Y.; Funabashi, T.; Kato, T. An Experimental Study on Active Power Control of Photovoltaic Power Generation for Supporting Grid Frequency Regulation. In Proceedings of the 2018 IEEE Power \& Energy Society General Meeting (PESGM), Portland, OR, USA, 5-10 August 2018; pp. 1-5.

80. Peng, Q.; Yang, Y.; Liu, T.; Blaabjerg, F. Coordination of Virtual Inertia Control and Frequency Damping in PV Systems for Optimal Frequency Support. CPSS Trans. Power Electron. Appl. 2020, 5, 305-316.

81. Azhar, I.F.; Putranto, L.M.; Hadi, S.P. Design of Battery Energy Storage System Control Scheme for Frequency Regulation for PV Integrated Power System. In Proceedings of the 2020 FORTEI-International Conference on Electrical Engineering (FORTEI-ICEE), Bandung, Indonesia, 23-24 September 2020; pp. 7-12. 